Article

\title{
Improving Handling Stability Performance of Four-Wheel Steering Vehicle Based on the $\mathrm{H} 2 / \mathrm{H} \infty$ Robust Control
}

\author{
Fei-Xiang Xu® , Xin-Hui Liu, Wei Chen, Chen Zhou * and Bing-Wei Cao
}

School of Mechanical and Aerospace Engineering, Jilin University, Changchun 130022, China; xufx17@mails.jlu.edu.cn (F.-X.X.); liuxh@jlu.edu.cn (X.-H.L.); chenwei_1979@jlu.edu.cn (W.C.); caobw16@mails.jlu.edu.cn (B.-W.C.)

* Correspondence: zhouchen17@mails.jlu.edu.cn; Tel.: +86-130-6627-6127

Received: 10 January 2019; Accepted: 23 February 2019; Published: 27 February 2019 updates

\begin{abstract}
Considering the demand for vehicle stability control and the existence of uncertainties in the four-wheel steering (4WS) system, the mixed $\mathrm{H} 2 / \mathrm{H} \infty$ robust control methodology of the 4WS system is proposed. Firstly, the linear 2DOF vehicle model, the nonlinear 8DOF vehicle model, the driver model, and the rear wheel electrohydraulic system model were constructed. Secondly, based on the yaw rate tracking strategy, the mixed $\mathrm{H} 2 / \mathrm{H} \infty$ controller was designed with the optimized weighting functions to guarantee system performance, robustness, and the robust stability of the 4WS vehicle stability control system. The $\mathrm{H} \infty$ method was applied to minimize the effects of modeling uncertainties, sensor noise, and external disturbances on the system outputs, and the $\mathrm{H} 2$ method was used to ensure system performance. Finally, numerical simulations based on Matlab/Simulink and hardware-in-the-loop experiments were performed with the proposed control strategy to identify its performance. The simulation and experimental results indicate that the handling stability of the 4 WS vehicle is improved by the $\mathrm{H} 2 / \mathrm{H} \infty$ controller and that the 4 WS system with the $\mathrm{H} 2 / \mathrm{H} \infty$ controller has better handling stability and robustness than those of the $\mathrm{H} \infty$ controller and the proportional controller.
\end{abstract}

Keywords: four wheel steering vehicle; handling stability; $\mathrm{H} 2 / \mathrm{H} \infty$ controller; yaw rate tracking; hardware-in-the-loop experiments

\section{Introduction}

With the development of electronic and control technologies, the four-wheel steering (4WS) system for automobiles has been actively studied as an effective vehicle maneuvering technology that can improve the maneuvering of vehicles at low speeds and enhance their stability at high speeds [1]. In order to enhance control performance, many studies have focused on the control strategies of the 4WS system since the first 4WS system became popular [2], especially its steering stability controller design, which has recently been a hot research topic [3-5].

Various control strategies have been performed on vehicle stability control, such as PID control [6], fuzzy control [7], and neural network control [8]. Although these control approaches enhance vehicle stability to a certain extent, neural network control needs a wide variety of experimental data, fuzzy control requires human experience to construct the fuzzy rules, and PID control shows weak robustness against external disturbances. Modern robust control theories have demonstrated some effective methods to deal with the above drawbacks $[9,10]$. Moreover, it is well known that the handling stability control containing various uncertainties is a highly nonlinear and complex process [11]. The 4WS vehicle stability control system is vulnerable to uncertainties, such as modeling uncertainties, 
external disturbances, measurement noises, and parameter variations. Hence, robust control urgently needs to be introduced into the 4WS system so as to reduce the influences of uncertainties on handling stability control.

The Ho optimal control theory has been widely used for robustness [12-16] since it was devised in the early 1980s by Zames and Francis. In the Ho approach, the designer from the outset specifies a model of system uncertainty, such as additive perturbation disturbance. The $\mathrm{H} \infty$ control method is best suited to cope with uncertainties of the 4WS vehicle maneuvering stability control. Zhao Wan-Zhong et al. [17] designed an $\mathrm{H} \infty$ controller for the active front steering (AFS) system. The simulation results showed that the AFS system can attenuate road interference quickly, and the driver is able to obtain a good road feel. Li Ming-Xing et al. [18] studied decoupling control with $\mathrm{H} \infty$ theory for 4 WS vehicles under varying longitudinal velocity. The simulations demonstrated that this $\mathrm{H} \infty$ control scheme can improve handling characteristics, safety, and comfort. Zhang Jin-Hua et al. [19] proposed an $\mathrm{H} \infty$ robust controller to improve the vehicle yaw stability under control system uncertainties. The coalition simulation results indicated that the designed $\mathrm{H} \infty$ controller can improve the vehicle handing stability performance. Qin Gang et al. [20] studied the $\mathrm{H} \infty$ control of four-wheel-independent-drive electric vehicles to deal with random time varying delays and achieved a real-time steady-state response. The results demonstrated the effectiveness of the $\mathrm{H} \infty$ controller by analyzing the control performance of the yaw rate and sideslip angle.

Although the $\mathrm{H} \infty$ control can improve the robustness of the control system, it does not take into account the system's dynamic performance [21,22]. The H2 control method can compensate the deficiency of $\mathrm{H} \infty$ control through minimizing the quadratic norm of the transfer function between the input signals and the plant's output signals [23,24]. However, the $\mathrm{H} 2$ controller ignores the robustness of the control system $[25,26]$. The mixed $\mathrm{H} 2 / \mathrm{H} \infty$ robust controller can integrate the advantages of both the $\mathrm{H} 2$ controller and the $\mathrm{H} \infty$ controller, which has been used in some practical fields [14,27-29]. Cheng Lin et al. [9] proposed the mixed $\mathrm{H} 2 / \mathrm{H} \infty$ robust controller for the stability control of the independent-drive electric vehicle. Zhao Wan-Zhong et al. [28] designed a mixed $\mathrm{H} 2 / \mathrm{H} \infty$ controller for the road feel of the electric power steering system based on a genetic algorithm. According to the $\mathrm{H} 2 / \mathrm{H} \infty$ theory, Wang Yun-Chao et al. [29] introduced the optimum controller of the multi-axle steering vehicle based on a yaw-rate tracking strategy.

However, the previous studies on the mixed $\mathrm{H} 2 / \mathrm{H} \infty$ controller only focused on the $4 \mathrm{WS}$ vehicle model in the vehicle stability controller design, ignoring the effect of the rear wheel steering actuator and the driver model. In this context, on one hand, this paper not only takes the rear wheel electrohydraulic system model into consideration, but also develops the actual rear wheel electrohydraulic system to conduct the hardware-in-the-loop experiments to demonstrate the $\mathrm{H} 2 / \mathrm{H} \infty$ controller's robustness against the modeling uncertainties of the rear wheel electrohydraulic system. On the other hand, a driver model is established to construct a driver-vehicle closed-loop system to investigate the influence of the driver's intention on the 4WS control system, and a double-lane change maneuver simulation was performed to demonstrate the validation of the $\mathrm{H} 2 / \mathrm{H} \infty$ controller used in the closed-loop 4 WS system. Thus, considering the rear wheel steering system and the driver model, an $\mathrm{H} 2 / \mathrm{H} \infty$ controller for vehicle stability was designed.

The handling stability of the $4 \mathrm{WS}$ vehicle is closely related to the sideslip angle and the yaw rate. Since the sideslip angle is difficult to measure, the yaw rate was used as the only feedback signal to control the 4WS vehicle. According to the yaw rate tracking strategy, a mixed $\mathrm{H} 2 / \mathrm{H} \infty$ robust controller design was used to study the stability control of the 4WS system. In order to make the H2/Hळ robust controller perform better in terms of system performance and robustness, the weighting functions were integrated into the $\mathrm{H} 2 / \mathrm{H} \infty$ robust controller based on the feedback tracking ability and the disturbance resistance. Simulations and hardware-in-the-loop experiments were conducted with the proposed control method to identify its performance. The numerical simulation and experimental results demonstrate that the $\mathrm{H} 2 / \mathrm{H} \infty$ controller can improve the $4 \mathrm{WS}$ vehicle handling stability. 
The rest of this paper is organized as follows: Section 2 constructs the mathematical models of the 4WS system; Section 3 studies the stability control strategy of the 4WS vehicle; Section 4 focuses on numerical simulations; Section 5 describes the hardware-in-the-loop experiments; and the final section presents conclusions.

\section{Mathematical Models of the 4WS System}

The mathematical models of the 4WS system consist of the two-degree-of freedom (2DOF) vehicle model for the controller design, the eight-degree-of freedom (8DOF) vehicle model used as a vehicle controlled plant, the driver model, and the rear wheel electrohydraulic system model.

\subsection{The 2DOF Vehicle Model for the Controller Design}

A 2DOF vehicle model is widely used as a reference model for the controller design of the vehicle steering system [30,31]. Both theory and experiment prove that the controllers based on the 2DOF vehicle model can work normally and represent the actual physical process of the vehicle steering system with great accuracy [32]. Thus, a 2DOF vehicle dynamics model was constructed to design the $\mathrm{H} 2 / \mathrm{H} \infty$ robust controller of the 4WS system, as shown in Figure 1 . As the reference coordinate system of the vehicle, the inertial coordinate frame $\left(x_{e}, y_{e}, z_{e}\right)$ is fixed on the ground, where the direction represented by the $z_{e}$ axis is perpendicular to the $\left(x_{e}, y_{e}\right)$ plane. The body coordinate system is represented by $(x, y, z)$ to describe the vehicle movement, where CG is the coordinate origin. The $(x, y, z)$ coordinate system rotates the yaw angle $\varphi$ towards the $\left(x_{e}, y_{e}, z_{e}\right)$. The vehicle runs at a constant speed $V$ measured at the CG point, and it rotates at a certain yaw velocity $r$. $\beta$ is the sideslip angle of the CG point.

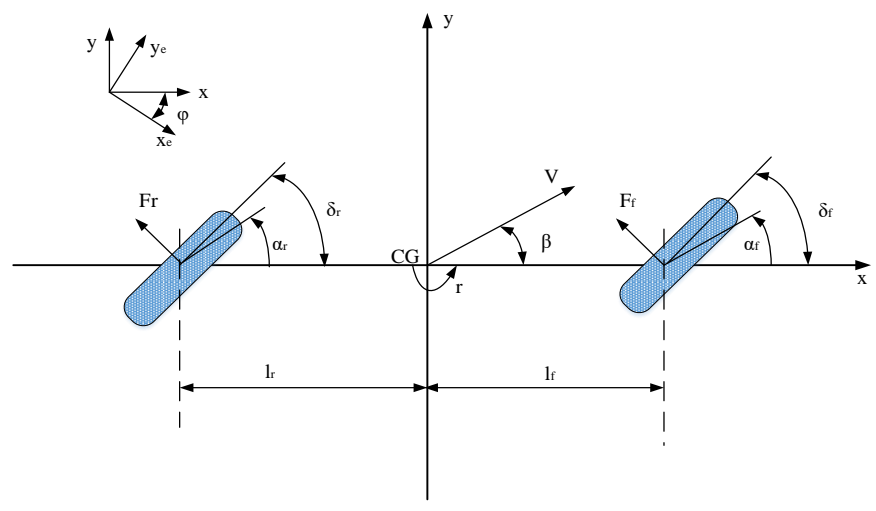

Figure 1. The 2DOF vehicle model.

Only considering lateral motion and yaw motion, the vehicle kinematics equation is derived from Newton's second law, which is shown below:

$$
\begin{gathered}
m V(\dot{\beta}+r) \cos \beta=F_{f} \cos \delta_{f}+F_{r} \cos \delta_{r} \\
I_{z} \dot{r}=l_{f} F_{f} \cos \delta_{f}-l_{r} F_{r} \cos \delta_{r}
\end{gathered}
$$

where $m$ denotes the vehicle mass; $F_{f}$ and $F_{r}$ are the lateral forces between the tire and the road surface of the front and rear wheels; $\delta_{f}$ and $\delta_{r}$ represent the front wheel angle and the rear wheel angle of the vehicle, respectively; $I_{z}$ denotes the moment of inertia of the vehicle around the $z$ axis; $l_{f}\left(l_{r}\right)$ is the distance between the gravity center and the front (rear) axle.

In general, $\delta_{f}$ and $\delta_{r}$ are quite small:

$$
\cos \delta_{f} \approx 1, \cos \delta_{r} \approx 1 .
$$


If $\beta$ is small and $V$ changes slowly, then

$$
\alpha_{f}=\delta_{f}-\beta-\frac{l_{f}}{V} r, \alpha_{r}=\delta_{r}-\beta+\frac{l_{r}}{V} r
$$

where $\alpha_{f}$ and $\alpha_{r}$ represent the slip angles of the front wheel and the rear wheel, respectively.

Based on the consideration of the cornering characteristics of tires, the following approximate linear models are adopted.

$$
F_{f}=C_{f} \alpha_{f}, F_{r}=C_{r} \alpha_{r}
$$

where $C_{f}$ and $C_{r}$ denote the cornering stiffness of the front wheel and the rear wheel, respectively.

Combined with Equations (1)-(4) mentioned above, the vehicle dynamics model is shown as follows.

$$
\begin{aligned}
& m V(\dot{\beta}+r)=-\left(C_{f}+C_{r}\right) \beta-\frac{l_{f} C_{f}-l_{r} C_{r}}{V} r+C_{f} \delta_{f}+C_{r} \delta_{r} \\
& I_{z} \dot{r}=-\left(l_{f} C_{f}-l_{r} C_{r}\right) \beta-\frac{l_{f} C_{f}+l_{r}{ }^{2} C_{r}}{V} r+l_{f} C_{f} \delta_{f}-l_{r} C_{r} \delta_{r} .
\end{aligned}
$$

The state space model is shown below:

$$
\left\{\begin{array}{l}
\dot{x}=A x+B u \\
y=C x+D u
\end{array}\right.
$$

where

$$
\begin{gathered}
x=\left[\begin{array}{ll}
\beta & r
\end{array}\right]^{T}, u=\left[\begin{array}{ll}
\delta_{f} & \delta_{r}
\end{array}\right]^{T}, y=\left[\begin{array}{ll}
\beta & r
\end{array}\right]^{T} \\
A=\left[\begin{array}{cc}
\frac{-\left(C_{f}+C_{r}\right)}{m V} & -1-\frac{l_{f} C_{f}-l_{r} C_{r}}{m V^{2}} \\
-\frac{l_{f} C_{f}-l_{r} C_{r}}{I_{z}} & -\frac{l_{f}^{2} C_{f}+l_{r}^{2} C_{r}}{I_{z} V}
\end{array}\right] \\
B=\left[\begin{array}{cc}
\frac{C_{f}}{m V} & \frac{C_{r}}{m V} \\
\frac{l_{f} C_{f}}{I_{z}} & -\frac{l_{r} C_{r}}{I_{z}}
\end{array}\right], C=\left[\begin{array}{ll}
1 & 0 \\
0 & 1
\end{array}\right], D=\left[\begin{array}{ll}
0 & 0 \\
0 & 0
\end{array}\right] .
\end{gathered}
$$

\subsection{The $8 D O F$ Vehicle Model and Model Validation}

\subsubsection{The 8 DOF Vehicle Model}

Although the 2DOF vehicle model mentioned above can be used for the controller design, it cannot be used to represent a vehicle-controlled plant because of its simplicity and linearity. In this study, a nonlinear 8DOF vehicle model is regarded as a vehicle-controlled plant for the 4WS control system's evaluations through computer simulations and hardware-in-the-loop experiments. Figure 2 shows the nonlinear 8DOF vehicle model, which mainly includes the rotational dynamics of the four wheels and the longitudinal, lateral, roll, and yaw motions of the vehicle.

(1) Longitudinal motion:

$$
\begin{gathered}
m\left(\dot{v}_{x}-v_{y} r\right)-m_{s} h \dot{r} \phi=\sum F_{x i} \\
\sum F_{x i}=\left(F_{x f l}+F_{x f r}\right) \cos \delta_{f}+\left(F_{x r l}+F_{x r r}\right) \cos \delta_{r}-\left(F_{y f l}+F_{y f r}\right) \sin \delta_{f}-\left(F_{y r l}+F_{y r r}\right) \sin \delta_{r} .
\end{gathered}
$$

(2) Lateral motion:

$$
\begin{gathered}
m\left(\dot{v}_{y}-v_{x} r\right)+m_{s} h \ddot{\phi}=\sum F_{y i} \\
\sum F_{y i}=\left(F_{y f l}+F_{y f r}\right) \cos s \delta_{f}+\left(F_{y r l}+F_{y r r}\right) \cos \delta_{r}+\left(F_{x f l}+F_{x f r}\right) \sin \delta_{f}+\left(F_{x r l}+F_{x r r}\right) \sin \delta_{r} .
\end{gathered}
$$


(3) Yaw motion:

$$
\begin{gathered}
I_{z} \dot{r}-I_{x z} \ddot{\phi}=\sum M_{z i} \\
\sum M_{z i}=\left[\left(F_{y f l}+F_{y f r}\right) \cos \delta_{f}+\left(F_{x f l}+F_{x f r}\right) \sin \delta_{f}\right] l_{f}-\left[\left(F_{y r l}+F_{y r r}\right) \cos \delta_{r}+\left(F_{x r l}\right.\right. \\
\left.\left.+F_{x r r}\right) \sin \delta_{r}\right] l_{r}+\left[\left(F_{x f l}-F_{x f r}\right) \cos \delta_{f}+\left(F_{y f r}-F_{y f l}\right) \sin \delta_{f}\right]\left(\frac{B_{f}}{2}\right) \\
+\left[\left(F_{x r l}-F_{x r r}\right) \cos \delta_{r}+\left(F_{y r r}-F_{y r l}\right) \sin \delta_{r}\right]\left(\frac{B_{r}}{2}\right) .
\end{gathered}
$$

(4) Roll motion:

$$
\begin{gathered}
I_{x} \ddot{\phi}+m_{s} h\left(v_{y}+v_{x} r\right)-I_{x z} \dot{r}=\sum M_{x} \\
\sum M_{x}=-\left(d_{\phi f}+d_{\phi r}\right) \dot{\phi}-\left(k_{\phi f}+k_{\phi r}\right) \phi+m_{s} g h \phi .
\end{gathered}
$$

(5) Wheels dynamics motion:

$$
I_{w} \dot{w}_{i}=T_{d i}-F_{x i} R_{w}-T_{b i}(i=f l, f r, r l, r r) .
$$

$v_{x}, v_{y}$ are the longitudinal and lateral velocities of the vehicle centroid; $m_{s}$ is the vehicle sprung mass; $\phi$ denotes the vehicle roll angle; $F_{x i}, F_{y i}$ represent the longitudinal and lateral forces acting on four wheels by the ground. $h$ is the height of the vehicle centroid; $I_{x z}$ is the momentum of inertia of vehicle around the $\mathrm{XZ}$ axis; $B_{f}, B_{r}$ denote the front and rear wheelbases; $d_{\phi f}, d_{\phi r}$ are the roll angle damping of the front and rear suspensions; $k_{\phi f}, k_{\phi r}$ represent the roll angle stiffness of the front and rear suspensions; $f l, f r, r l, r r$ denote the front left wheel, front right wheel, rear left wheel, and rear right wheel; $T_{d i}$ is the wheel driving moment; $T_{b i}$ is the wheel braking moment.

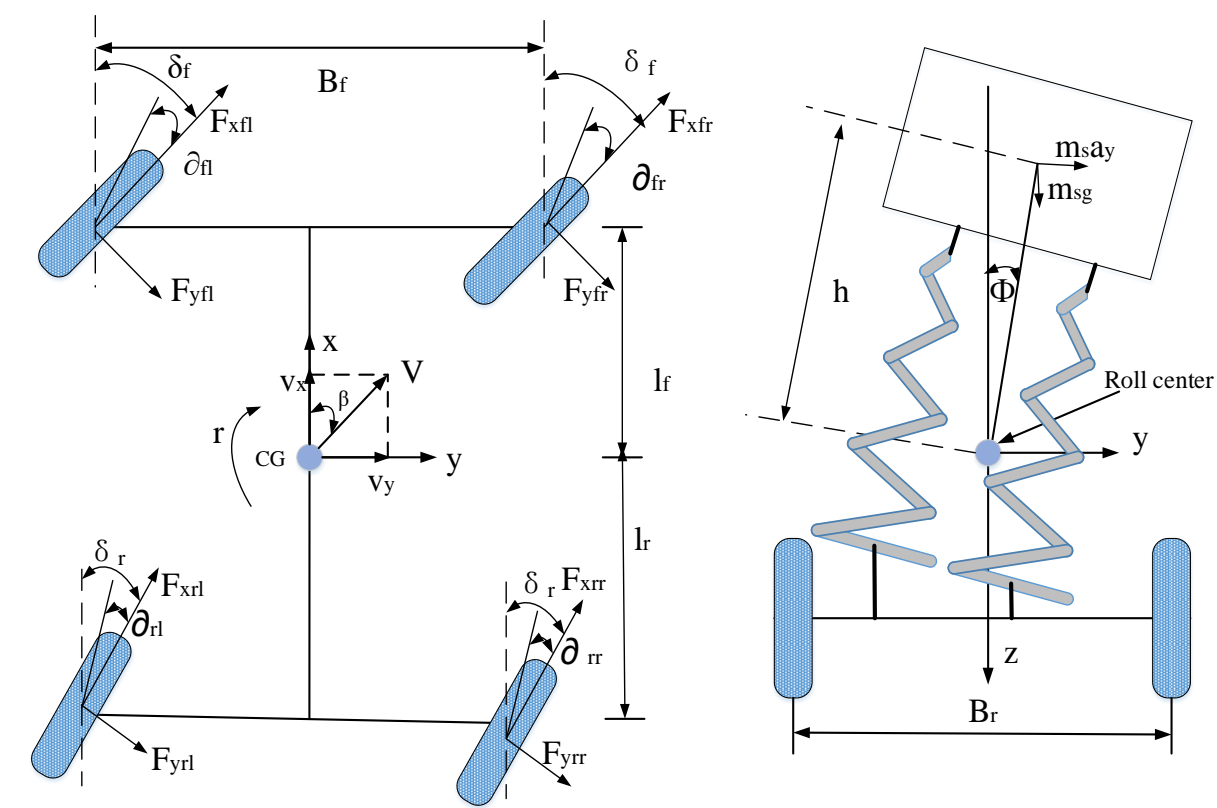

Figure 2. The nonlinear 8DOF vehicle model.

When the vehicle runs at high speeds, the tire would enter into the non-linear area. In this context, a nonlinear tire model should be built to represent the nonlinearity of the tire forces. This study adopts the well-known Dugoff tire model, and the detained modeling of the Dugoff tire can be found in [33].

\subsubsection{Model Validation}

To demonstrate the effectiveness and accuracy of the proposed nonlinear vehicle model, the full-vehicle model is constructed in Carsim software to contrast the 8DOF vehicle model built in the 
Simulink. The simulation condition $\left(\delta_{f}=3 * p i / 180 *(3.33 t), \delta_{r}=0, V=20 \mathrm{~m} / \mathrm{s}\right)$ is set under the full-vehicle model and the $8 \mathrm{DOF}$ vehicle model. The simulation results for the sideslip angle, yaw rate, and lateral acceleration are shown in Figure 3. As can be seen in Figure 3, the magnitudes and trends of the full-vehicle model and the $8 \mathrm{DOF}$ vehicle model results are roughly consistent, which proves the correctness of the $8 \mathrm{DOF}$ vehicle model. Thus, the $8 \mathrm{DOF}$ vehicle model is used as the vehicle model in this paper to evaluate the 4WS control system.

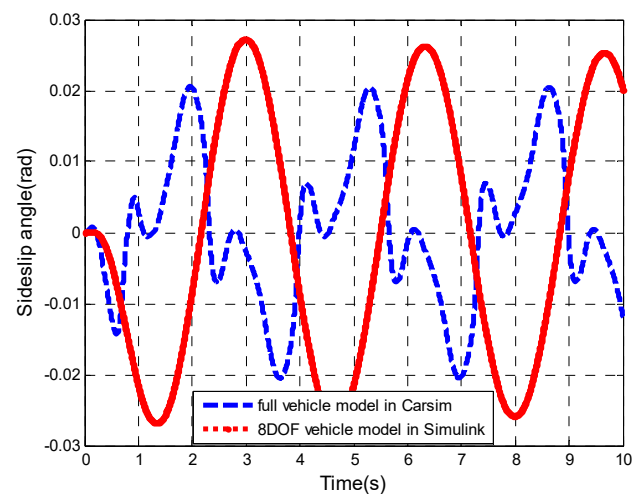

(a)
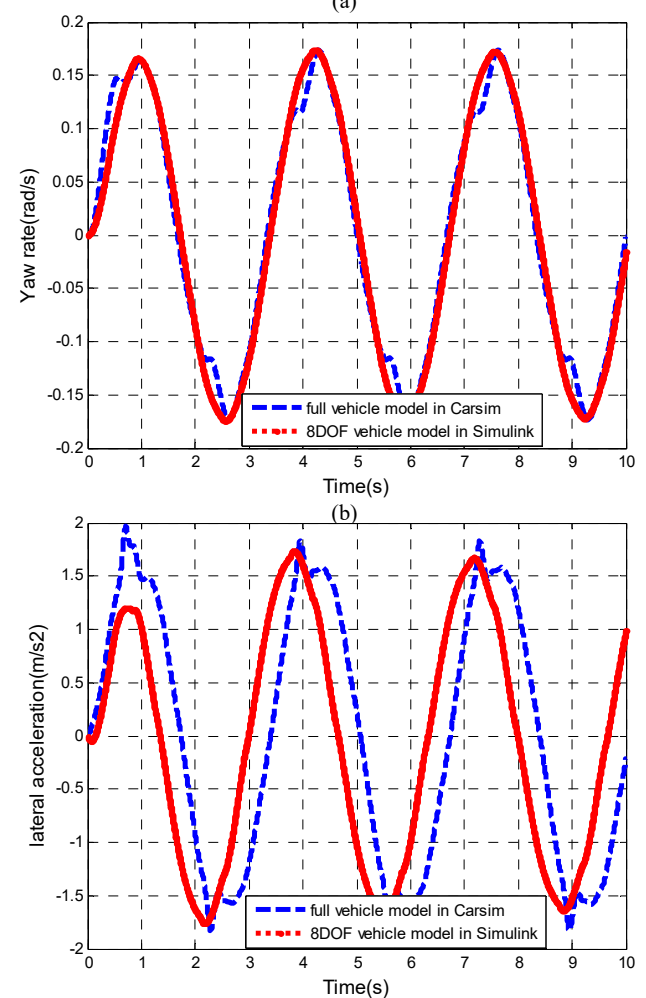

(c)

Figure 3. 8DOF vehicle model validation: (a) sideslip angle comparison; (b) yaw rate comparison; (c) lateral acceleration comparison.

\subsection{The Driver Model}

According to the "preview-follow" theory [34,35], the driver model is established, and the driver-vehicle closed-loop system is presented in Figure 4. $f(t)$ represents the road input; $T$ denotes the driver's preview time; $T_{\mathrm{C}}$ is the correction time; $C_{0}$ denotes the correction parameter; $\delta_{\mathrm{sw}}{ }^{*}$ is the ideal steering wheel angle; $T_{d}$ is the lag time of the driver's response; $T_{h}$ is the lag time of the driver's control response; $\delta_{\mathrm{sw}}$ is the actual steering-wheel angle; $y(t)$ denotes the lateral displacement; $\ddot{y} / \delta_{\mathrm{sw}}{ }^{*}$ represents the transfer function of the vehicle. 


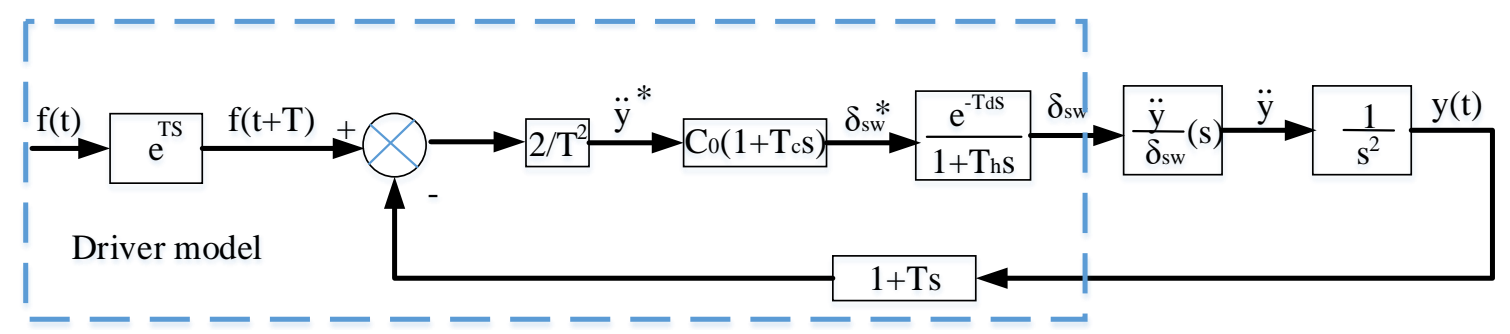

Figure 4. The driver-vehicle closed-loop system.

The transfer function of the driver model is shown as follows.

$$
\delta_{\mathrm{sw}}=\frac{1-T_{d} s / 2}{1+\left(T_{h}+T_{d} / 2\right) s+T_{h d} / 2 s^{2}} \frac{2 C_{0}}{T^{2}}\left(\left(1+T_{c} s\right) f(s) e^{T s}-\left(1+\left(T+T_{\mathcal{c}}\right) s+T T_{\mathcal{c}} s^{2}\right) y(s)\right) .
$$

\subsection{The Rear Wheel Electrohydraulic System Model}

The rear wheel electrohydraulic system was used to realize the vehicle's rear wheel rotation based on electrohydraulic proportional control technology, and its schematic diagram is shown in Figure 5. Firstly, the controller sends a current to the proportional electromagnetic valve. Secondly, the spool of the proportional electromagnetic valve is moved. Thirdly, the hydraulic oil flows through the proportional electromagnetic valve to drive the steering cylinder's motion. Finally, the steering cylinder drives the rocker arm and the pull rod to rotate the tire.

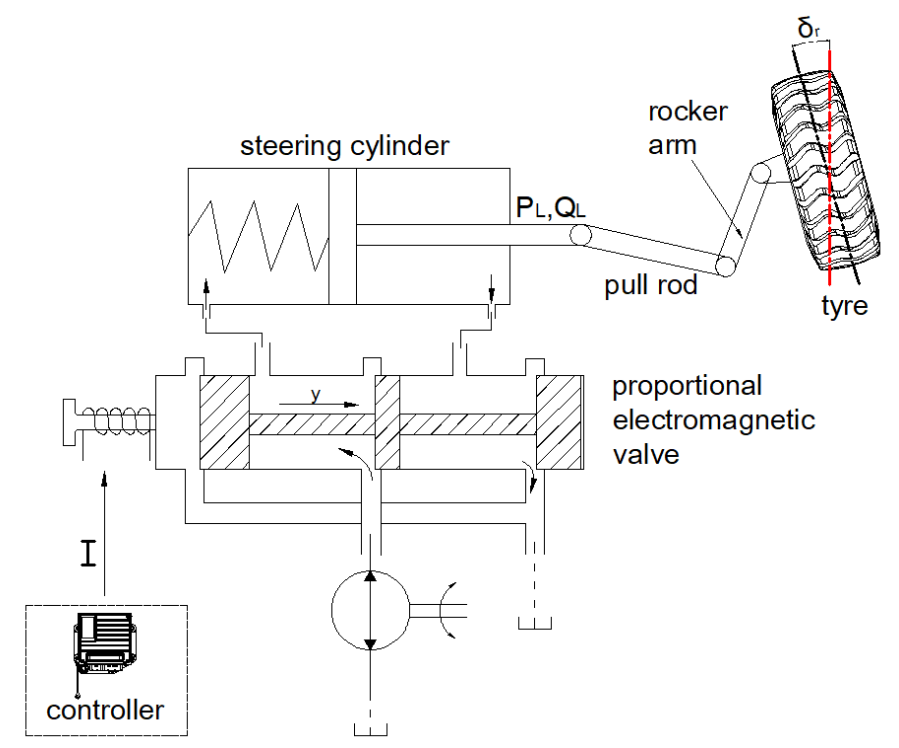

Figure 5. The schematic diagram of the rear wheel steering system.

The relationship between the output current $I$ of the controller and the spool displacement $y$ of the proportional electromagnetic valve is shown as follows.

$$
K_{m} I=M_{j} \frac{d^{2} y}{d t^{2}}+B_{y} \frac{d y}{d t}+K_{1}\left(y+y_{0}\right)
$$

where $M_{j}$ represents the spool quality of the reversal valve; $B_{y}$ denotes the viscosity damping coefficient of the spool; $K_{1}$ is the spring stiffness; $y_{0}$ represents the pre-compression of the spring.

The load flow equation of the proportional electromagnetic valve is shown below.

$$
Q_{L}=K_{q h} y-K_{p h} P_{L}
$$


where $Q_{L}$ is the load flow; $K_{q h}$ denotes the zero flow gain of the spool; $K_{p h}$ represents the pressure-flow rate of the spool; $P_{L}$ is the load pressure.

The mathematical model of the hydraulic cylinder is shown as follows.

$$
\begin{gathered}
Q_{L}=A_{c} \frac{d y_{g}}{d t}+C_{L} P_{L}+\frac{V_{e}}{4 \beta_{e}} \frac{d P_{L}}{d t} \\
A_{C} P_{L}=M_{t} \frac{d^{2} y_{g}}{d t^{2}}+B_{t} \frac{d y_{g}}{d t}+K_{L} y_{g}+F_{L}
\end{gathered}
$$

where $A_{c}$ is the equivalent area; $y_{g}$ represents the piston displacement; $C_{L}$ is the leakage coefficient; $V_{e}$ is the equivalent volume; $\beta_{e}$ denotes the elastic modulus; $M_{t}$ is the total mass; $B_{t}$ denotes the viscous damping coefficient; $K_{L}$ denotes the spring stiffness of the load; $F_{L}$ is the external load force.

The rear wheel angle by means of equivalent linearization method is shown below.

$$
\delta_{r}=k_{r} y_{g}
$$

Based on Laplace transform, the transfer function of the rear wheel electrohydraulic system can be shown as follows.

$$
G_{a c t}(s)=\frac{\delta_{r}(s)}{I(s)}=\frac{K_{r} K_{m} \frac{K_{q h}}{A_{c}}}{s\left(\frac{s^{2}}{\omega_{h}{ }^{2}}+\frac{2 \zeta_{h}}{\omega_{h}} s+1\right)\left(M_{j} s^{2}+B_{y} s+K_{1}\right)} .
$$

In the rear wheel electrohydraulic system, the hydraulic cylinder is a major influence on the dynamic response. Therefore, the equation mentioned above can be expressed approximately as follows.

$$
G_{a c t}(s)=\frac{K_{r} K_{m} \frac{K_{q h}}{A_{c}}}{K_{1} s\left(\frac{s^{2}}{\omega_{h}^{2}}+\frac{2 \zeta_{h}}{\omega_{h}} s+1\right)} .
$$

\section{The Stability Control Strategy of the 4WS Vehicle}

The control strategy of the 4WS vehicle stability aims to improve the vehicle handling stability, which can be divided into two parts: track the yaw rate and make the sideslip angle zero. In the actual control process, the uncertainties are unavoidable in a real 4WS system. Another control objective is to eliminate the effects of modeling uncertainties, the noise signal, and the external disturbance signals in the 4WS system. In this context, the schema of the 4WS vehicle stability control is shown in Figure 6.

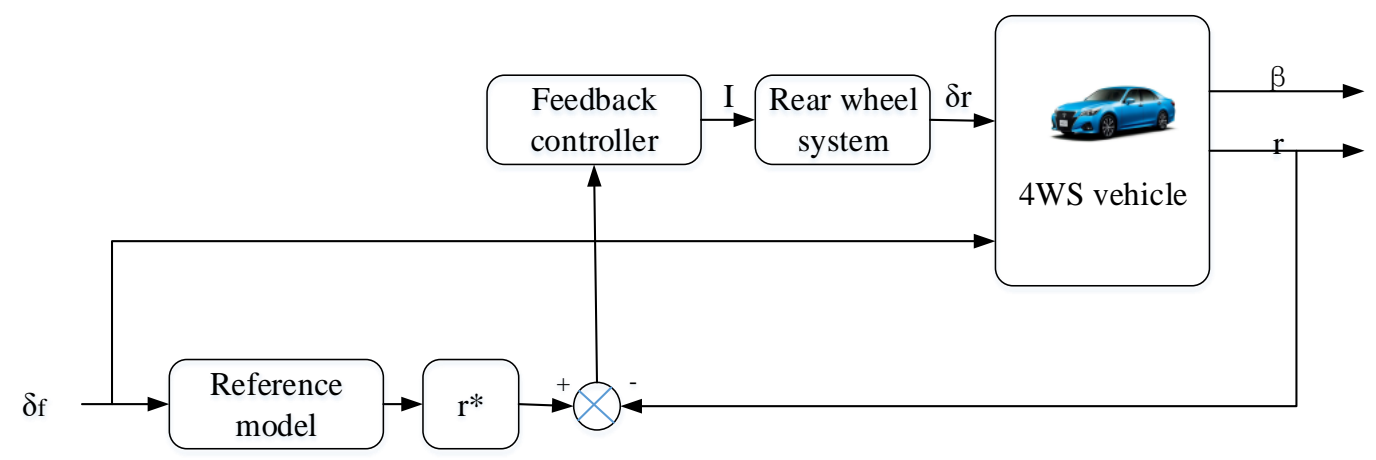

Figure 6. 4WS vehicle stability control schema ( $r^{*}$ denotes the ideal yaw rate).

The reference model defines the ideal yaw rate of the 4WS vehicle, and the desired yaw rate is assumed to be as follows [11,36]:

$$
\frac{r^{*}}{\delta_{f}}=\frac{s / 300+0.8}{s / 10+1}
$$


The feedback controller is designed to minimize the yaw rate error between the 4WS vehicle and the reference model. In other words, yaw rate tracking can be transformed to follow the ideal reference model. Based on the $\mathrm{H} 2 / \mathrm{H} \infty$ feedback controller, the control current is transferred into the rear wheel electrohydraulic system, and the rear wheel angle is then obtained. Finally, the handling stability of the $4 \mathrm{WS}$ vehicle is achieved.

\subsection{The Uncertainty Description}

The 4WS vehicle stability control system is vulnerable to uncertainties that are unavoidable in a real control system. Hence, uncertainties must be taken into consideration to improve the robustness and robust stability of the 4WS control system. The uncertainties are of two classes: disturbances and dynamic perturbations. The former consists of external disturbances, sensor noises, actuator noises, etc. The latter denotes the modeling uncertainty, which is the difference between the mathematical model and the actual control system.

In this paper, the 4 WS vehicle modeling uncertainty, the rear wheel electrohydraulic system modeling uncertainty, the yaw rate sensor noise, and the external disturbances are regarded as the uncertainties, as shown in Figure 7. $\Delta_{\text {act }}$ denotes the rear wheel electrohydraulic system modeling uncertainty; $\Delta_{v}$ represents the $4 \mathrm{WS}$ vehicle modeling uncertainty; $n, f, T_{f}$ are the yaw rate sensor noise, the lateral interference force, and the yaw interference torque, respectively; $G_{r e f}$ denotes the transfer function of the reference model; $G_{a c t}$ represents the transfer function of the rear wheel electrohydraulic system; $G$ stands for the transfer function of the $4 \mathrm{WS}$ vehicle model.

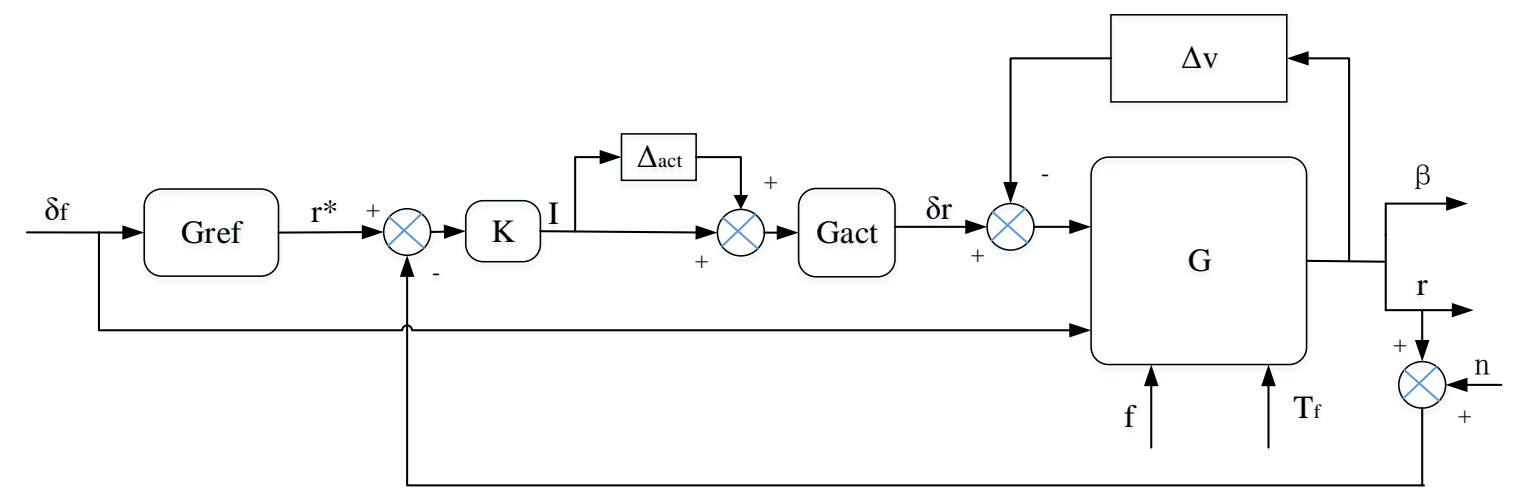

Figure 7. Block diagram of the robust control considering uncertainties.

The external disturbance signals are considered in the 4WS vehicle model. The $4 \mathrm{WS}$ vehicle model based on external disturbances can be described as follows.

$$
\begin{gathered}
m V(\dot{\beta}+r)=-\left(C_{f}+C_{r}\right) \beta-\frac{l_{f} C_{f}-l_{r} C_{r}}{V} r+C_{f} \delta_{f}+C_{r} \delta_{r}+f \\
I_{z} \dot{r}=-\left(l_{f} C_{f}-l_{r} C_{r}\right) \beta-\frac{l_{f}^{2} C_{f}+l_{r}^{2} C_{r}}{V} r+l_{f} C_{f} \delta_{f}-l_{r} C_{r} \delta_{r}+T_{f} .
\end{gathered}
$$

Equation (20) is transformed into a state space model, which is shown below.

$$
\left[\begin{array}{c}
\dot{\beta} \\
\dot{r}
\end{array}\right]=\left[\begin{array}{cc}
\frac{-\left(C_{f}+C_{r}\right)}{m V} & \frac{l_{r} C_{r}-l_{f} C_{f}}{m V^{2}}-1 \\
\frac{l_{r} C_{r}-l_{f} C_{f}}{I_{z}} & -\frac{l_{f}^{2} C_{f}+l_{r}^{2} C_{r}}{I_{z} V}
\end{array}\right]\left[\begin{array}{l}
\beta \\
r
\end{array}\right]+\left[\begin{array}{cccc}
\frac{C_{f}}{m V} & \frac{1}{m V} & 0 & \frac{C_{r}}{m V} \\
\frac{l_{f} C_{f}}{I_{z}} & 0 & \frac{1}{I_{z}} & -\frac{l_{r} C_{r}}{I_{z}}
\end{array}\right]\left[\begin{array}{c}
\delta_{f} \\
f \\
T_{f} \\
\delta_{r}
\end{array}\right] .
$$

The dynamic perturbations can be represented by inserting one single perturbation block $\Delta$ into the mathematical model. As shown in Figure $7, \Delta_{\text {act }}$ denotes the input multiplicative perturbation in the rear wheel electrohydraulic system model, and $\Delta_{v}$ represents the inverse additive perturbation in the 4 WS vehicle model. The linear fractional transformation (LFT) is used to transform dynamic 
perturbations into a standard configuration to represent how the model uncertainties affect the input/output relationship [37]. The dynamic perturbations can be denoted as a unified framework, as shown in Figure 8.

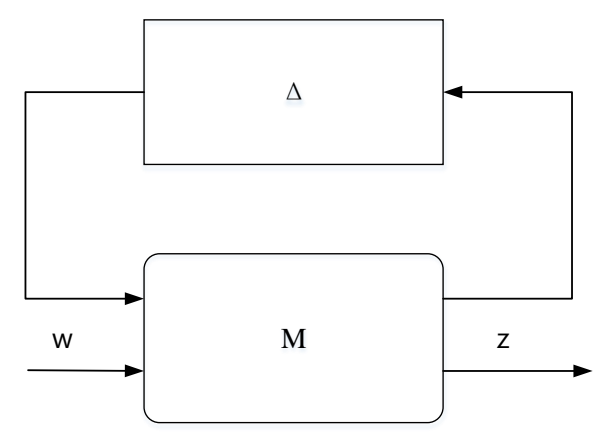

Figure 8. Standard $M-\Delta$ configuration.

$F(M, \Delta)$ is called the LFT of interconnection transfer function of matrix $\mathrm{M}$ to perturbation $\Delta$, which can be written as follows.

$$
\begin{gathered}
F(M, \Delta)=M_{22}+M_{21} \Delta\left(I-M_{11} \Delta\right)^{-1} M_{12} \\
M=\left[\begin{array}{ll}
M_{11} & M_{12} \\
M_{21} & M_{22}
\end{array}\right] .
\end{gathered}
$$

Based on LFT, the relationship between input $w$ and output $z$ of the control system can be shown below.

$$
z=F(M, \Delta) w .
$$

The rear wheel electrohydraulic system model and the 4WS vehicle model uncertainties can be described uniformly by Figure 8, and their interconnection transfer function matrixes are shown as follows.

$$
\begin{aligned}
M_{a c t} & =\left[\begin{array}{cc}
0 & I \\
G_{a c t} & G_{a c t}
\end{array}\right] \\
M_{0} & =\left[\begin{array}{ll}
-G & G \\
-G & G
\end{array}\right]
\end{aligned}
$$

where $M_{a c t}$ and $M_{0}$ represent interconnection transfer function matrixes of the rear wheel electrohydraulic system model and the $4 \mathrm{WS}$ vehicle model, respectively; $G$ denotes the transfer function of the $4 \mathrm{WS}$ vehicle model.

The whole system model with dynamic perturbations can be described further based on the following LFT, as shown in Figure 9.

$$
\left[\begin{array}{l}
\beta \\
r
\end{array}\right]=F\left(M_{s y s}, \Delta\right)\left[\begin{array}{c}
\delta_{f} \\
f \\
T_{f} \\
I
\end{array}\right]
$$

where $M_{s y s}$ denotes the interconnection transfer function matrix of the whole system model; $\Delta$ represents the whole dynamic perturbations. 


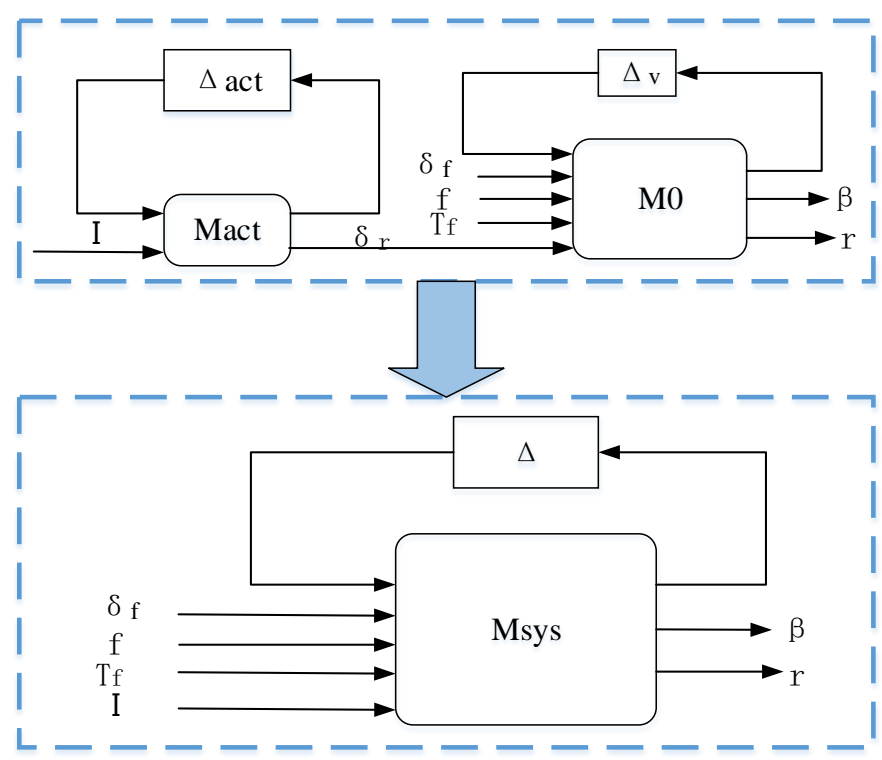

Figure 9. Linear fractional transformation (LFT) representation of 4WS vehicle stability control system with dynamic perturbations.

\subsection{The $H 2 / H \infty$ Robust Control Strategy}

In order to compensate the robustness against the unavoidable uncertainties in the real 4WS control system, the feedback controller was designed based on the mixed $\mathrm{H} 2 / \mathrm{H} \infty$ control theory. The $\mathrm{H} \infty$ controller was formulated as a minimization problem of the infinitive norm of a closed-loop transfer function matrix. The $\mathrm{H} 2$ theory was studied to improve system performance. As a generalization of the $\mathrm{H} \infty$ control problem, the $\mathrm{H} 2 / \mathrm{H} \infty$ control theory was used to find an optimal controller that can improve the robustness and performance of the $4 \mathrm{WS}$ control system.

The $\mathrm{H} 2 / \mathrm{H} \infty$ standard design problem is shown in Figure 10, where $w$ is the input signal; $u$ is the feedback input signal; $z_{\infty}$ and $z_{2}$ are the outputs of the $\mathrm{H} 2 / \mathrm{H} \infty$ controller indexes; $y$ is the output signal; $G(s)$ is the generalized controlled object; $K(s)$ is the feedback controller; $\Delta$ represents the uncertainties.

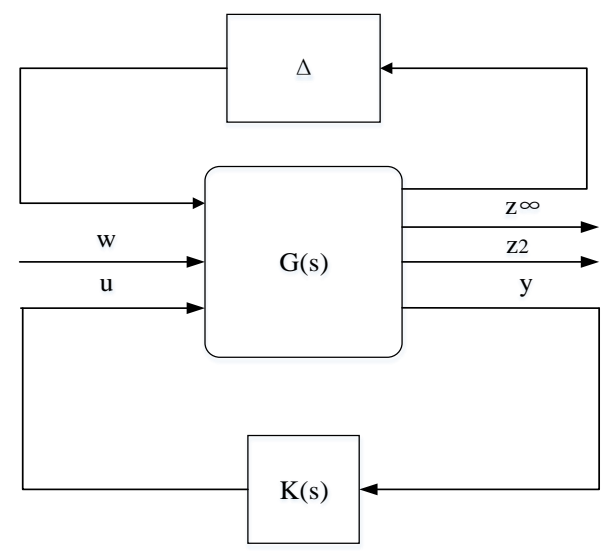

Figure 10. The standard $\mathrm{H} 2 / \mathrm{H} \infty$ design problem.

$G(s)$ is a linear, time-invariant system, which can be described by the state space model, as shown below.

$$
\left\{\begin{array}{l}
\dot{x}=A x+B_{1} w+B_{2} u \\
z_{\infty}=C_{1} x+D_{11} w+D_{12} u \\
z_{2}=C_{2} x+D_{21} w+D_{22} u \\
y=C_{y} x+D_{y 1} w+D_{y 2} u
\end{array}\right.
$$


where $A, B_{1}, B_{2}, C_{1}, D_{11}, D_{21}, C_{2}, D_{21}, D_{22}, C_{y}, D_{y 1}, D_{y 2}$ are the parameter matrixes of the state space.

Equation (26) is represented as follows.

$$
\left[\begin{array}{c}
z_{\infty} \\
z_{2} \\
y
\end{array}\right]=G(s)\left[\begin{array}{l}
w \\
u
\end{array}\right]=\left[\begin{array}{ll}
G_{11}(s) & G_{12}(s) \\
G_{21}(s) & G_{22}(s)
\end{array}\right]\left[\begin{array}{c}
w \\
u
\end{array}\right]
$$

Suppose $G(s)$ meets the following requirements:

(1) $\left(A, B_{1}\right)$ is stable, and $\left(C_{1}, A\right)$ can be measured.

(2) $\left(A, B_{2}\right)$ is stable, and $\left(C_{2}, A\right)$ can be measured.

Based on the assumptions mentioned above, the $\mathrm{H} 2 / \mathrm{H} \infty$ control theory mainly takes advantage of the output signal to design a suitable controller and obtains the appropriate feedback control input shown below.

$$
u=K(s) y \text {. }
$$

The designed $\mathrm{H} 2 / \mathrm{H} \infty$ controller can make the closed loop system meet different characteristics with respect to the following requirements.

(1) The closed-loop system is internally stable. In other words, all eigenvalues of the state matrix of the closed-loop system are in the left half open plane.

(2) The $\mathrm{H} 2 / \mathrm{H} \infty$ norm of $T_{z w}$ is minimized or less than a given value, as shown below.

$$
\left\{\begin{array}{c}
\min \left\|T_{z_{2} w}(s)\right\|_{\infty} \\
\left\|T_{z_{\infty} w}(s)\right\|_{\infty}<\gamma
\end{array}\right.
$$

The feedback controller $K(s)$ can be expressed by state space, which is shown below.

$$
\left\{\begin{array}{c}
\dot{x}_{K}=A_{K} x_{K}+B_{K} y \\
u=C_{K} x_{K}+D_{K} y
\end{array}\right.
$$

where $A_{K}, B_{K}, C_{K}, D_{K}$ are the parameter matrixes of the feedback controller $K(s) ; x_{K}$ is the state vector of $K(s)$.

By applying Equation (30) into Equation (27), the closed-loop system can be expressed as follows.

$$
\left[\begin{array}{c}
\dot{\varepsilon} \\
z_{\infty} \\
z_{2}
\end{array}\right]=\left[\begin{array}{cc}
A_{C} & B_{C} \\
C_{C 1} & D_{C 11} \\
C_{C 2} & D_{C 21}
\end{array}\right]\left[\begin{array}{c}
\varepsilon \\
w
\end{array}\right]
$$

where

$$
\begin{aligned}
& \varepsilon=\left[\begin{array}{c}
x \\
x_{K}
\end{array}\right] \\
& A_{C}=\left[\begin{array}{cc}
A+B_{2} D_{K} C_{y} & B_{2} C_{K} \\
B_{K} C_{y} & A_{K}
\end{array}\right] \\
& B_{C}=\left[\begin{array}{c}
B_{1}+B_{2} D_{K} D_{y 1} \\
B_{K} D_{y 1}
\end{array}\right] \\
& C_{C 1}=\left[\begin{array}{ll}
C_{1}+D_{12} D_{K} C_{y} & D_{12} C_{K}
\end{array}\right. \\
& C_{C 2}=\left[\begin{array}{ll}
C_{2}+D_{22} D_{K} C_{y} & D_{22} C_{K}
\end{array}\right] \\
& D_{C 11}=\left[D_{11}+D_{12} D_{K} D_{y 1}\right] \\
& D_{C 21}=\left[D_{21}+D_{22} D_{K} D_{y 1}\right] \text {. }
\end{aligned}
$$


The goal of the $\mathrm{H} 2 / \mathrm{H} \infty$ controller design is to find the best robust controller $K(s)$ that minimizes the sensitivity function and complementary sensitivity function. On that basis, the weighting functions are taken into account in the $\mathrm{H} 2 / \mathrm{H} \infty$ robust controller design based on the feedback tracking ability and the disturbances resistance. The control system with the sensitivity functions and the weighting functions are shown in Figure 11.

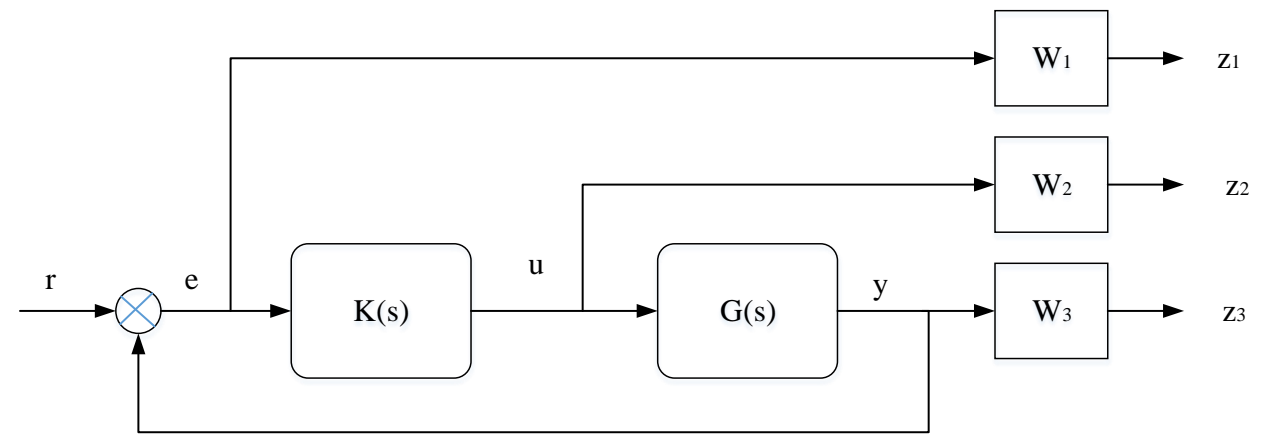

Figure 11. Mixed sensitivity problem with weighting functions $\left(W_{1}, W_{2}, W_{3}\right.$ are the weighting functions).

The sensitivity function $S$ reflects good tracking and great disturbance attenuation of the control system. KS can save control energy of the system. The complementary sensitivity function $T$ can enhance the robust stability of the control system. These sensitivity functions can be represented as follows.

$$
\begin{gathered}
S=(I+G K)^{-1} \\
K S=K(I+G K)^{-1} \\
T=(I+G K)^{-1} G K
\end{gathered}
$$

Based on the sensitivity functions and the weighting functions, the $\mathrm{H} 2 / \mathrm{H} \infty$ controller design aims at solving the following optimization problem.

$$
\min _{K}\left\|\begin{array}{c}
W_{1} S \\
W_{2} K S \\
W_{3} T
\end{array}\right\| \leq 1 .
$$

\subsection{Weighting Function Selection}

As mentioned above, the weighting functions are used to make the 4WS control system have better system performance and robustness. For the mixed sensitivity problem, in general, the selection criteria of the weighting functions are described below.

(1) $W_{1}$ is on behalf of the tracking and disturbance resistance of the control system, and it needs to possess low pass characteristics. Therefore, $W_{1}$ is the low pass transfer function. $W_{2}$ reflects the requirements of the sensitivity function $K S$ and can reduce the control energy output. $W_{2}$ is defined as a constant. $W_{3}$ is responsible for the requirements of the complementary sensitivity function $T$ and needs to have high pass characteristics. Hence, $W_{3}$ is represented by the high pass transfer function.

(2) In order to reduce the order of the designed robust controller and make it easier to be applied in the $4 \mathrm{WS}$ vehicle, the weighting functions $W_{1}$ and $W_{2}$ are selected as the first-order transfer functions in this paper.

Based on the selection principles mentioned above, the weighting functions can be denoted as follows.

$$
\begin{gathered}
W_{1}=\frac{s / M+w_{0}}{s+w_{0} A} \\
W_{2}=\text { const } \\
W_{3}=\frac{s+w_{0} / M}{s+w_{0}}
\end{gathered}
$$


where $A$ represents the maximum steady-state error, $A<1 ; w_{0}$ is the expected bandwidth; $M$ denotes the peak sensitivity; const denotes a constant.

Significant efforts and extensive experiments are needed to find the best weighting functions, which are defined as follows.

$$
\begin{gathered}
W_{1}=\frac{0.2 s+1}{s+0.001} \\
W_{2}=0.01 \\
W_{3}=\frac{s+0.2}{s+1} .
\end{gathered}
$$

The bode diagrams of the weighting functions $W_{1}$ and $W_{3}$ are shown in Figure 12. Obviously, $W_{1}$ and $W_{3}$ are the low pass and high pass transfer functions, respectively.

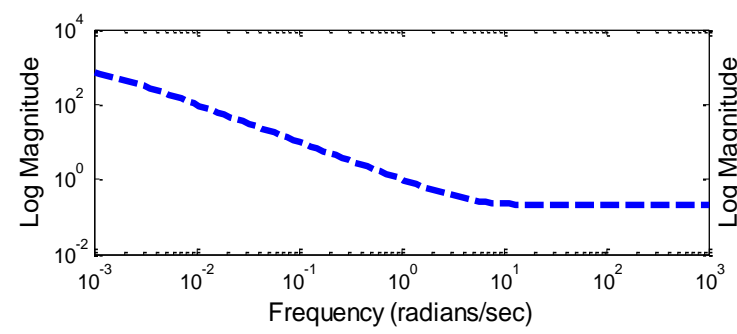

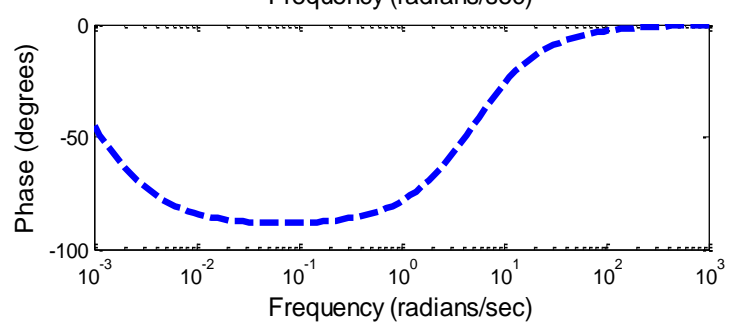

(a)
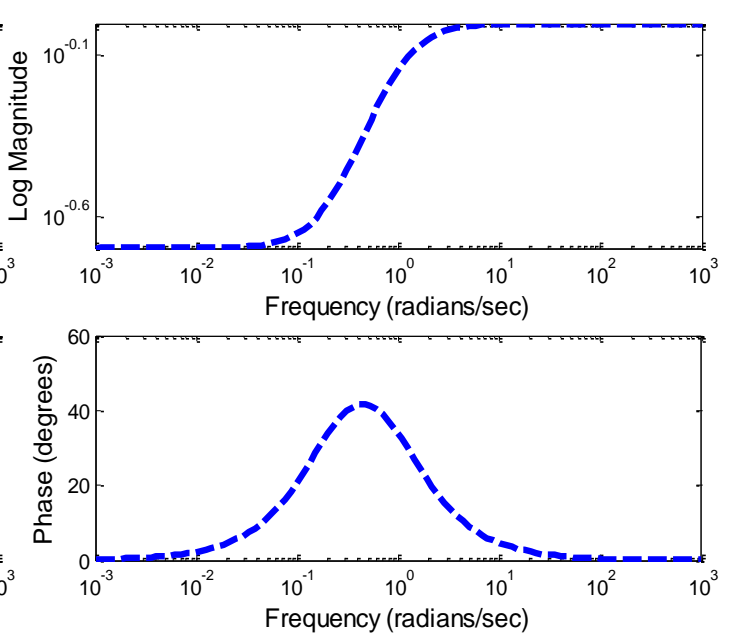

(b)

Figure 12. The bode diagrams of the weighting functions: (a) $W_{1}$; (b) $W_{3}$.

\subsection{The Design of $\mathrm{H} 2 / \mathrm{H} \infty$ Robust Controller}

The $\mathrm{H} 2 / \mathrm{H} \infty$ robust controller is designed to improve the robustness and performance of the 4WS stability control system, and the control structure is shown in Figure 13. The control system inputs are the front wheel angle $\delta_{f}$, the yaw rate sensor noise $n$, the lateral interference force $f$, and the yaw interference torque $T_{f}$. The current $I$ is the output of the $\mathrm{H} 2 / \mathrm{H} \infty$ robust controller. The outputs of the control system are divided into three parts: $z_{1}, z_{2}$, and $z_{3} . z_{1}$ is responsible for good tracking, external disturbances attenuation, and the noise restrain ability of the control system. $z_{2}$ reflects the energy consumption of the controller. $z_{3}$ reflects the robust stability of the control system.

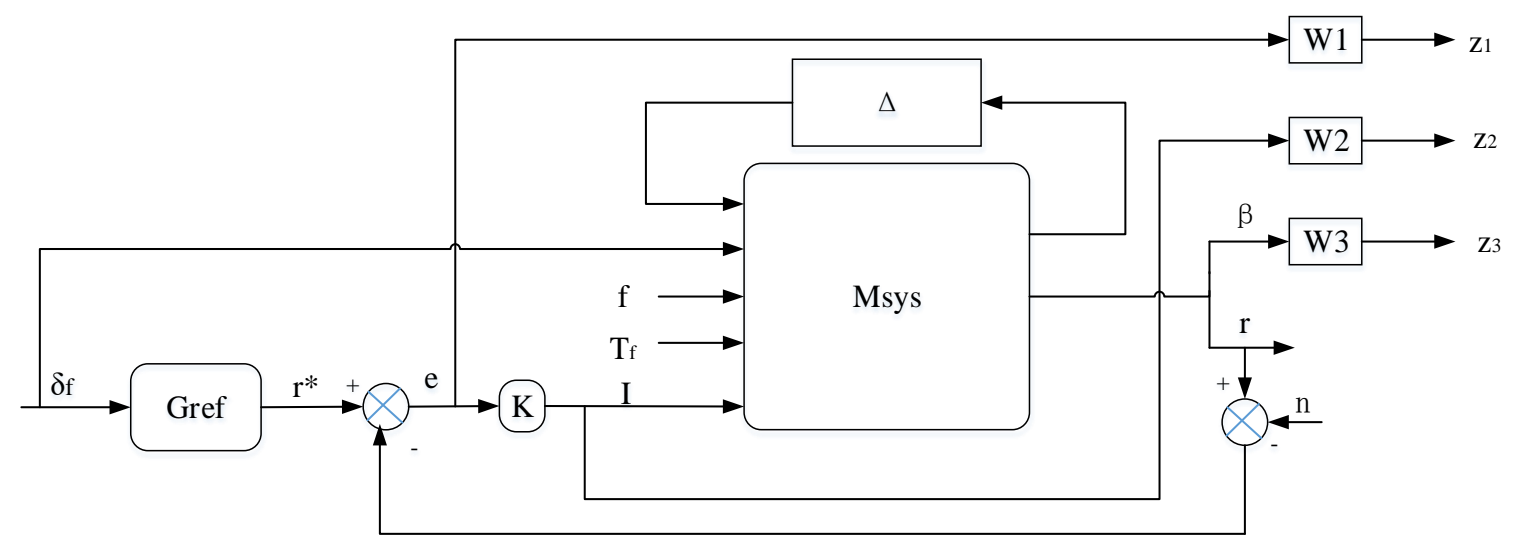

Figure 13. The stability control structure of the $4 \mathrm{WS}$ vehicle. 
According to the stability control structure of the 4WS vehicle mentioned above, the standard $\mathrm{H} 2 / \mathrm{H} \infty$ design problem in this paper can be shown in Figure 14. The $\mathrm{H} \infty$ norm is responsible for improving the control system's robustness and reducing output energy. The $\mathrm{H} 2$ controller is used to enhance the control system's dynamic performance. The generalized system can be described as follows.

$$
\left[\begin{array}{l}
z_{1} \\
z_{2} \\
z_{3}
\end{array}\right]=F(P, K)\left[\begin{array}{c}
\delta_{f} \\
f \\
T_{f} \\
n
\end{array}\right]
$$

where

$$
\begin{gathered}
F(P, K)=P_{22}+P_{21} K\left(I-P_{11} K\right)^{-1} P_{12} \\
P=\left[\begin{array}{ll}
P_{11} & P_{12} \\
P_{21} & P_{22}
\end{array}\right] .
\end{gathered}
$$

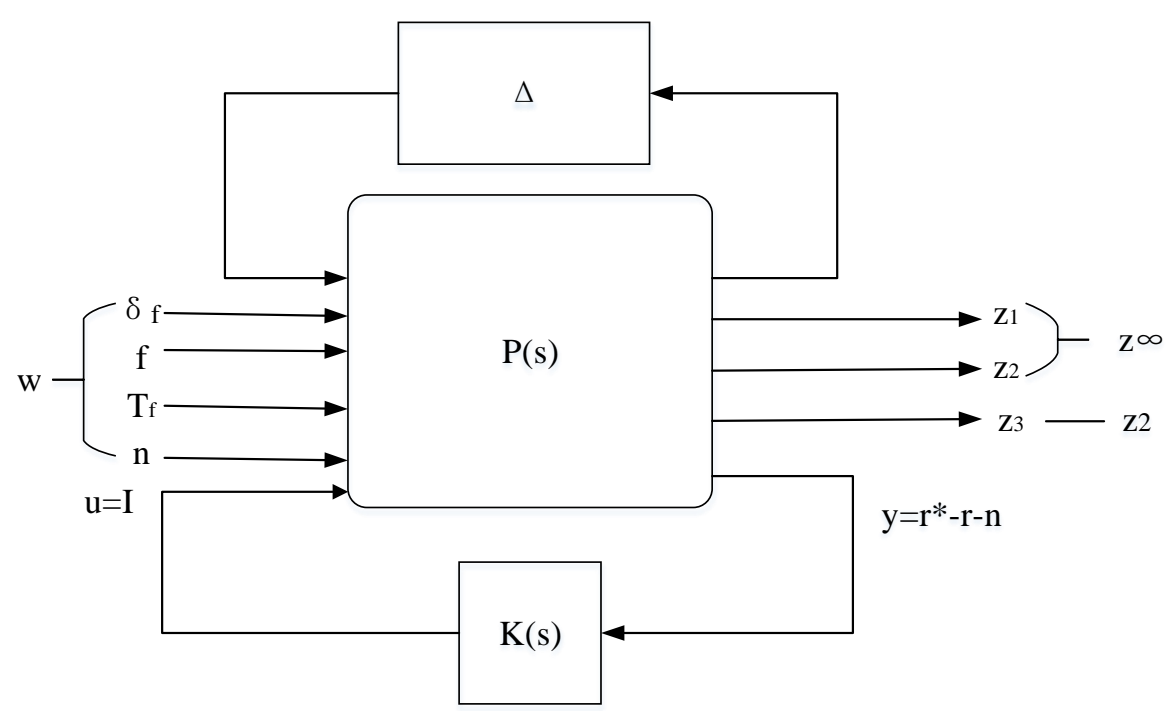

Figure 14. Standard $\mathrm{H} 2 / \mathrm{H} \infty$ design problem of the $4 \mathrm{WS}$ vehicle.

\section{Simulations and Results Analysis}

The simulations based on Matlab/Simulink were performed with the proposed $\mathrm{H} 2 / \mathrm{H} \infty$ control strategy to identify the 4 WS vehicle's yaw rate tracking ability and path tracking performance. Moreover, the $\mathrm{H} \infty$ controller and the traditional proportional controller were also designed to contrast the performance of the proposed $\mathrm{H} 2 / \mathrm{H} \infty$ controller. A proportional controller is usually used to control real 4WS vehicles, and the ratio of rear wheel angle to front wheel angle is defined as follows [38].

$$
K=\frac{\delta_{r}}{\delta_{f}}=\frac{-l_{r}+\frac{m l_{f} V^{2}}{C_{r} L}}{l_{f}+\frac{m l_{r} V^{2}}{C_{f} L}}\left(L=l_{f}+l_{r}\right) .
$$

The parameters utilized in the numerical simulations are shown in Table 1.

A $\mathrm{H} 2 / \mathrm{H} \infty$ controller was designed for the $4 \mathrm{WS}$ vehicle at a velocity of $90 \mathrm{~km} / \mathrm{h}$. The LMI (linear matrix inequality) Control Toolbox was used to obtain the $\mathrm{H} 2 / \mathrm{H} \infty$ controller, which can guarantee that the $H 2$ performance index $\left\|T\left(z_{2} w\right)\right\|<0.61$ and the $H \infty$ index $\left\|T\left(z_{\infty} w\right)\right\|<0.27$. In order to verify the performance of the robust $\mathrm{H} 2 / \mathrm{H} \infty$ controller applied in the $4 \mathrm{WS}$ vehicle, four steering maneuvers (step steering maneuver, sinusoidal steering maneuver, fishhook maneuver, and double-lane change maneuver) were simulated in a MATLAB/Simulink environment using the nonlinear 8DOF vehicle model. 
Table 1. The parameters of the 4WS vehicle.

\begin{tabular}{cc}
\hline Parameter & Value \\
\hline$m(\mathrm{~kg})$ & 5950 \\
$I_{z}\left(\mathrm{~kg} \cdot \mathrm{m}^{2}\right)$ & 8600 \\
$l_{f}(\mathrm{~m})$ & 1.2 \\
$l_{r}(\mathrm{~m})$ & 1.8 \\
$C_{f}(\mathrm{~N} / \mathrm{rad})$ & 55,000 \\
$C_{r}(\mathrm{~N} / \mathrm{rad})$ & 45,000 \\
$K_{r}$ & 1.4 \\
$K_{m}(\mathrm{~N} / \mathrm{A})$ & 130 \\
$K_{1}(\mathrm{~N} / \mathrm{m})$ & 3000 \\
$w_{0}(\mathrm{rad} / \mathrm{s})$ & 79.5 \\
$\varepsilon_{0}$ & 0.21 \\
$K_{q h}\left(\mathrm{~m}^{2} / \mathrm{s}\right)$ & 1.35 \\
$A_{C}\left(\mathrm{~m}^{2}\right)$ & $1.129 \times 10^{-3}$ \\
\hline
\end{tabular}

\subsection{Step Steering Maneuver}

Firstly, the nominal performance of the 4WS stability control system was studied. The step responses of the front wheel angle input were studied to verify the nominal performance of the 4WS vehicle. Suppose the $4 \mathrm{WS}$ vehicle runs at a velocity $90 \mathrm{~km} / \mathrm{h}$, and the road friction coefficient is set as 0.85 (dry road). Figure 15 shows the input signal of the front wheel angle. Figure 16 depicts the sideslip angle response and the yaw rate response among the $\mathrm{H} \infty$ controller, the proportional controller, and the $\mathrm{H} 2 / \mathrm{H} \infty$ controller.

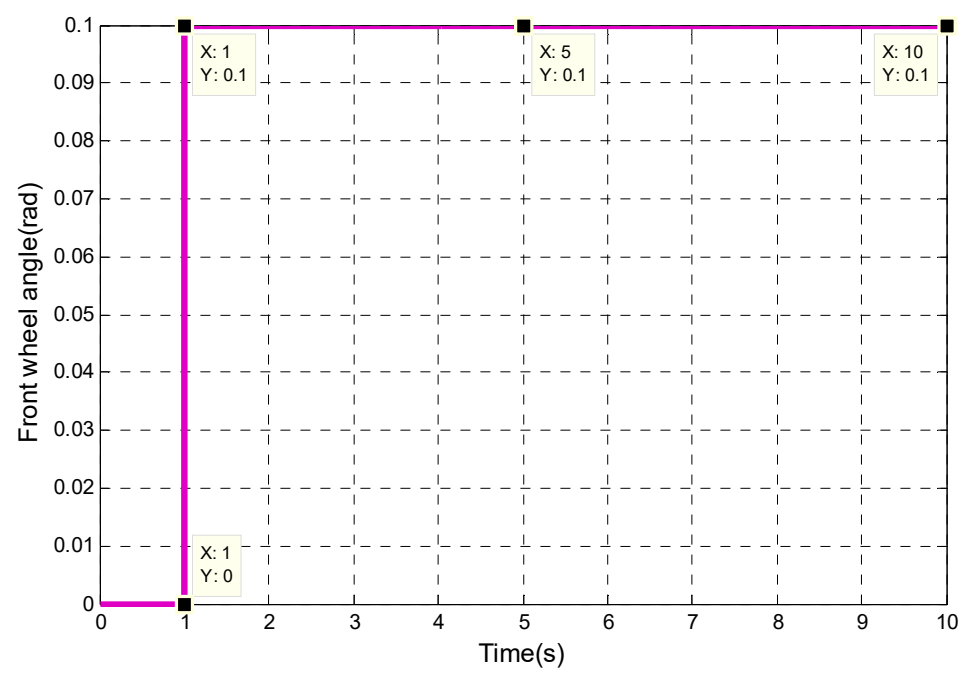

Figure 15. The front wheel angle step input.

As can be seen in Figure 16a, the sideslip angle with the proportional controller had large overshoot, and the sideslip angle with the $\mathrm{H} \infty$ controller presented certain fluctuations. Compared with the $\mathrm{H} \infty$ controller and the proportional controller, the $\mathrm{H} 2 / \mathrm{H} \infty$ controller made the sideslip angle response more stable. As shown in Figure 16b, when the $4 \mathrm{WS}$ vehicle was equipped with the $\mathrm{H} 2 / \mathrm{H} \infty$ and $\mathrm{H} \infty$ controllers, the steady state errors between the yaw rate and the desired yaw rate were almost zero, while the steady state error of the vehicle equipped with the proportional controller was $0.02 \mathrm{rad} / \mathrm{s}$. Compared with the $\mathrm{H} \infty$ controller, the yaw rate of the 4 WS vehicle with the $\mathrm{H} 2 / \mathrm{H} \infty$ controller responses was quicker and more stable. It can be concluded that the $\mathrm{H} 2 / \mathrm{H} \infty$ controller outperformed the $\mathrm{H} \infty$ controller and the proportional controller in terms of yaw rate tracking and path tracking. 


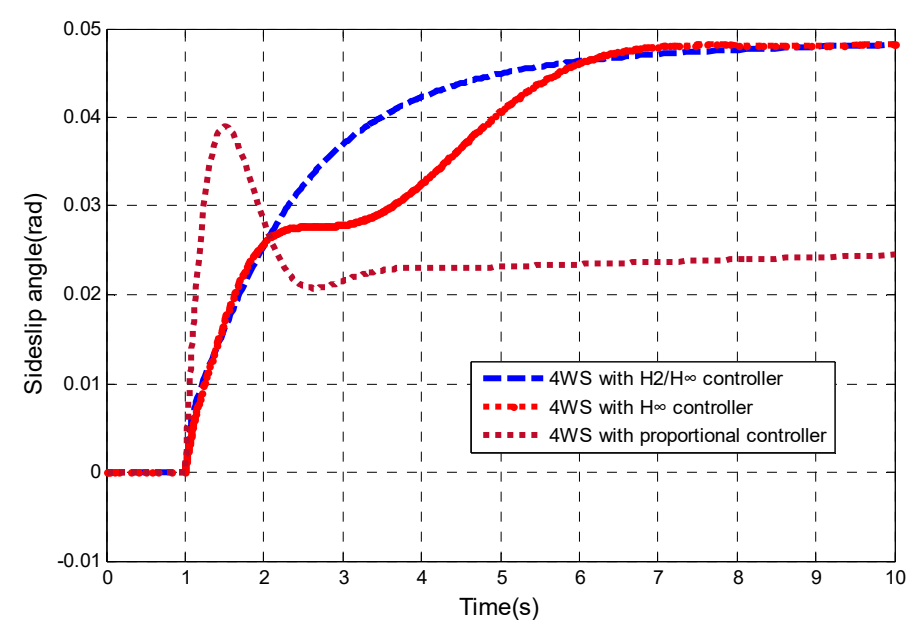

(a)

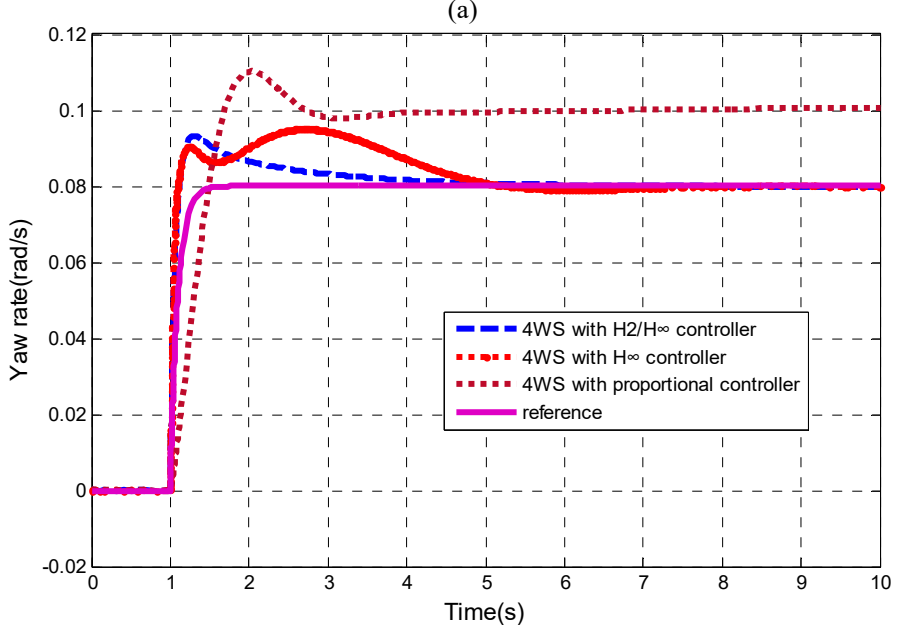

(b)

Figure 16. The step responses of the front wheel angle: (a) sideslip angle response; (b) yaw rate response.

Secondly, in order to demonstrate the disturbances resistance capability of the designed controller, the side wind and yaw rate sensor noise were taken under the step input of the front wheel angle mentioned above. A $15 \mathrm{~m} / \mathrm{s}$ side wind (Level $7: 13.9 \mathrm{~m} / \mathrm{s} \leq V_{\text {wind }} \leq 17.1 \mathrm{~m} / \mathrm{s}$ ) was considered to simulate the external interferences, as shown in Figure 17. According to the aerodynamic theory, the lateral interference force and the yaw interference torque can be expressed as follows [37].

$$
\begin{gathered}
f=\frac{1}{2} C_{f x} \rho A V_{a}^{2} \\
T_{f}=\frac{1}{2} C_{M z} \rho A L V_{a}^{2} \\
V_{a}^{2}=V^{2}+V_{\text {wind }}{ }^{2}
\end{gathered}
$$

where $C_{f x}$ is the lateral force coefficient; $C_{M z}$ denotes the yaw torque coefficient; $\rho$ is the air density; $V_{a}$ represents the flow rate of the synthetic airflow; $V_{\text {wind }}$ is the wind velocity.

The sensitivity to the given disturbances is defined as the average absolute relative error between the yaw rate or sideslip angle without disturbances and that with disturbances, which can be expressed as follows.

$$
\lambda_{\text {sen }}=\sum_{k=1}^{n} \frac{\left|y_{\text {with }}(k)-y_{\text {without }}(k)\right|}{\left|y_{\text {without }}(k)\right|} / n
$$

where $y_{\text {without }}(k)$ denotes the yaw rate or sideslip angle without disturbances at the $k$ th moment; $y_{\text {with }}(k)$ is the yaw rate or sideslip angle with disturbances at the kth moment; $n$ represents the numbers of the yaw rate or sideslip angle in the disturbance periods. 

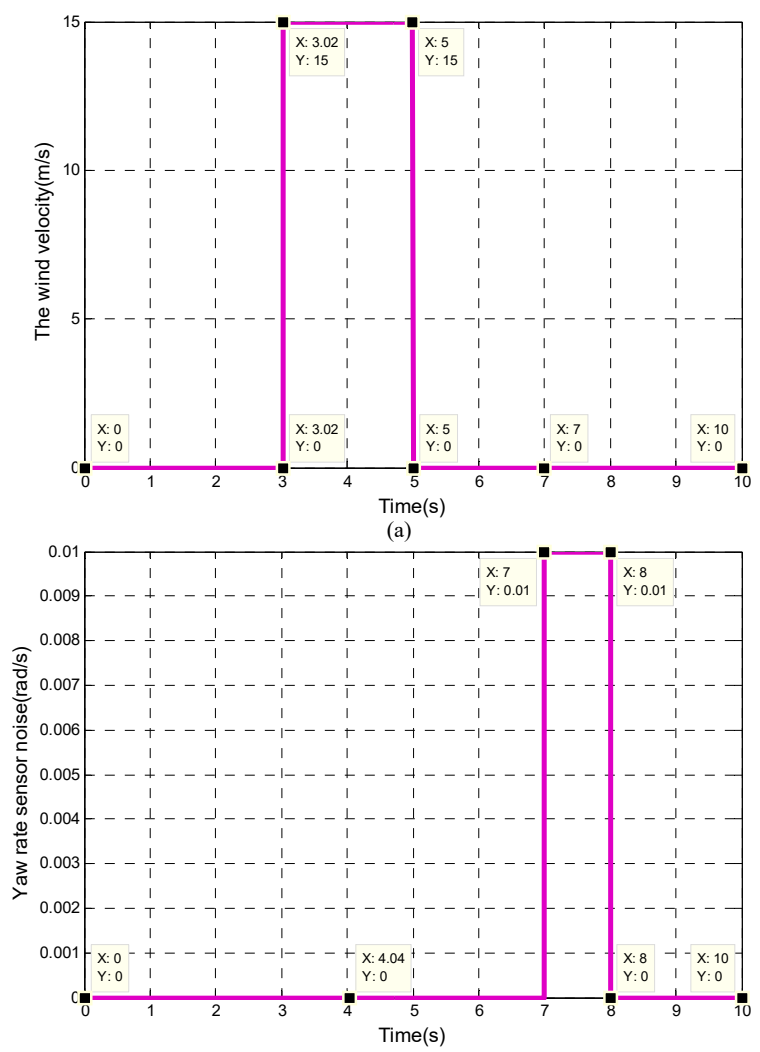

(b)

Figure 17. The disturbances signals: (a) side wind; (b) yaw rate sensor noise.

When the sensitivity $\lambda_{\text {sen }}$ to the given disturbances is greater than its threshold $\lambda_{\max }$, the 4WS vehicle equipped with the designed controller is vulnerable to disturbances; otherwise, the proposed controller is robust against disturbances. $\lambda_{\max }$ can be defined by various experts and automobile manufacturers, and it is set as 0.08 in this paper.

Figure 18 depicts the sideslip angle response and the yaw rate response under disturbances. As shown in Figure 18, under the disturbances of the side wind in a 3-5 s period and the yaw rate sensor noise in a 7-8 s period, the sideslip angle and the yaw rate of the 4WS vehicles with the $\mathrm{H} 2 / \mathrm{H} \infty$ controller and the $\mathrm{H} \infty$ controller were not disturbed, while that of the vehicle equipped with the proportional controller showed large fluctuations, and the sensitivities $\lambda_{\text {sen }}$ of the sideslip angle and the yaw rate to the disturbances were greater than 0.08 . It was concluded that the $\mathrm{H} 2 / \mathrm{H} \infty$ controller and the $\mathrm{H} \infty$ controller are more robust than the proportional controller. The yaw rate's settling time and the overshoot of the $4 \mathrm{WS}$ vehicle with the $\mathrm{H} 2 / \mathrm{H} \infty$ controller were lower than that of the $\mathrm{H} \infty$ controller, which shows that the $\mathrm{H} 2 / \mathrm{H} \infty$ controller made the $4 \mathrm{WS}$ vehicle more robust than the $\mathrm{H} \infty$ controller.

Finally, the robust stability of the 4WS control system was verified. Figure 19 shows the frequency response of the maximum singular value of perturbation block $\Delta$ transfer function matrix, and $\Delta$ reflects the mathematical modeling uncertainties. Figure 19 depicts the robust stability of the control system with respect to the modeling uncertainties. It can be seen that the maximum singular value of $\Delta$ was less than 1 and that the $\mathrm{H} 2 / \mathrm{H} \infty$ controller and the $\mathrm{H} \infty$ controller had great robust stability. 


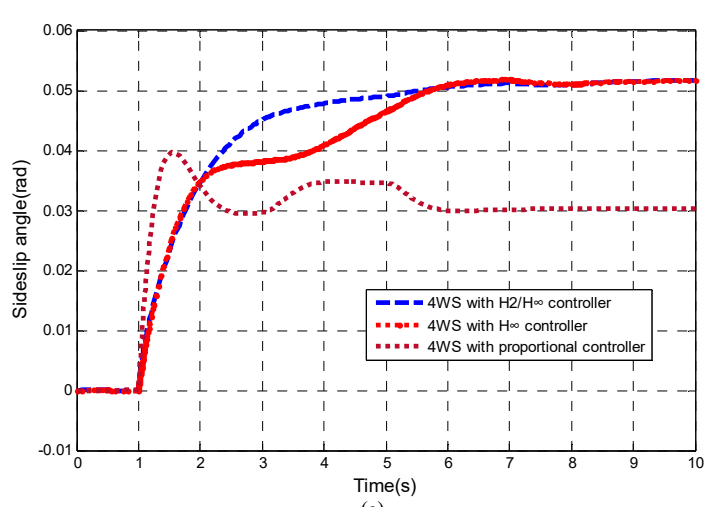

(a)

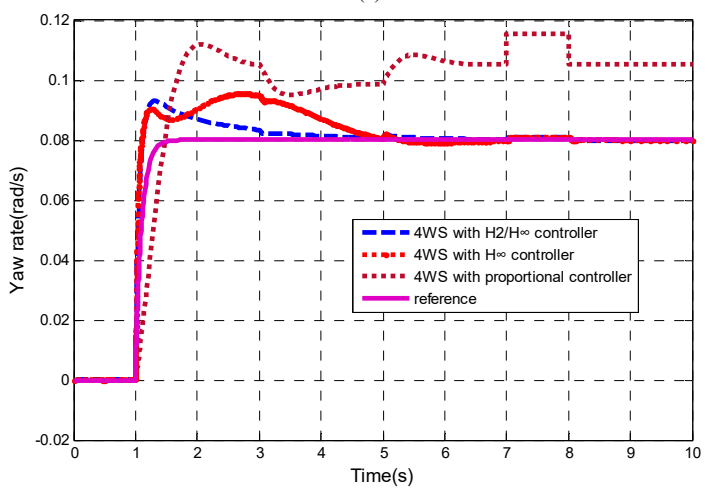

(b)

Figure 18. The step responses of the front wheel angle under interferences: (a) sideslip angle response; (b) yaw rate response.

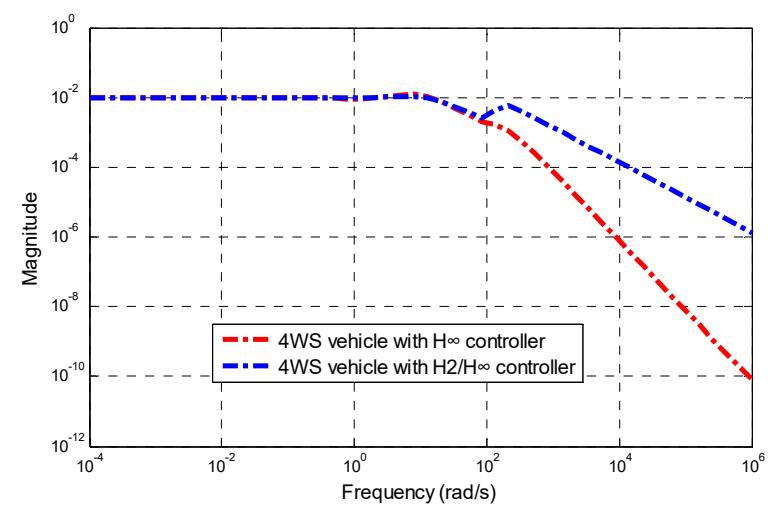

Figure 19. The frequency response of the maximum singular value of perturbation block $\Delta$ transfer function matrix.

\subsection{Sinusoidal Steering Maneuver}

To evaluate the tracking performance of the 4WS control system with the designed controller, a steering test on the sinusoidal wave maneuver was performed. The sinusoidal input of the front wheel angle is shown in Figure 20. The 4WS vehicle initially ran at $120 \mathrm{~km} / \mathrm{h}$, and the road friction coefficient was set as 0.6 (wet road). The simulation results are shown in Figure 21.

As can be seen in Figure 21a, the 4WS vehicle with the $\mathrm{H} 2 / \mathrm{H} \infty$ controller had a smaller sideslip angle than those of the $\mathrm{H} \infty$ controller and the proportional controller, which shows that the $\mathrm{H} 2 / \mathrm{H} \infty$ controller gave the $4 \mathrm{WS}$ vehicle the best path tracking capability. We can see from Figure $21 \mathrm{~b}$ that the 4WS vehicle equipped with the $\mathrm{H} 2 / \mathrm{H} \infty$ controller was fully capable of tracking the ideal yaw rate, while those of the $\mathrm{H} \infty$ controller and the proportional controller had yaw rate tracking errors. It was concluded that the 4WS system with the $\mathrm{H} 2 / \mathrm{H} \infty$ controller outperformed that with the $\mathrm{H} \infty$ controller and the proportional controller in terms of path tracking and yaw rate tracking capabilities. 


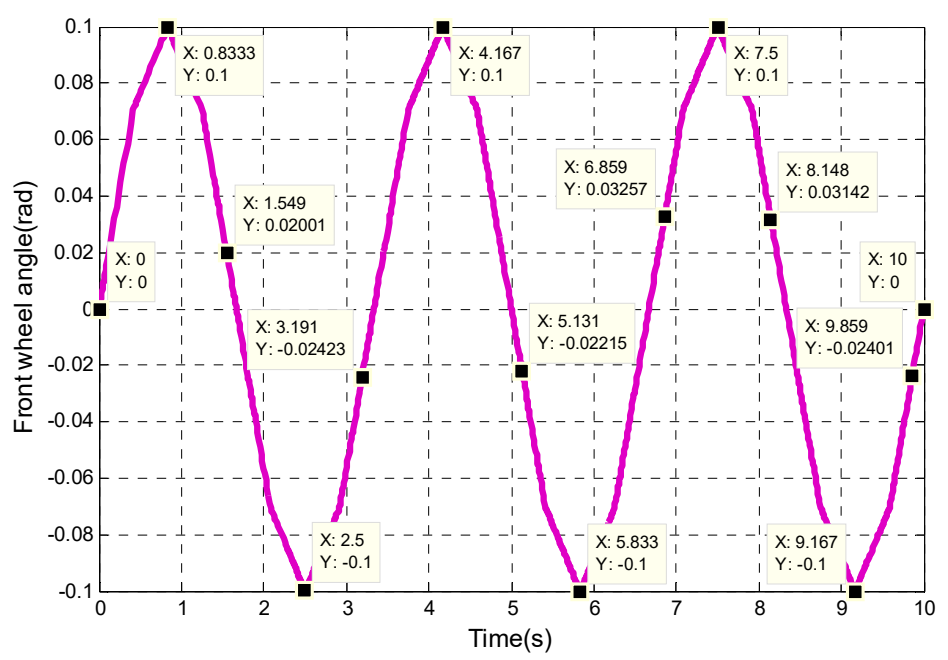

Figure 20. The sinusoidal input of the front wheel angle.
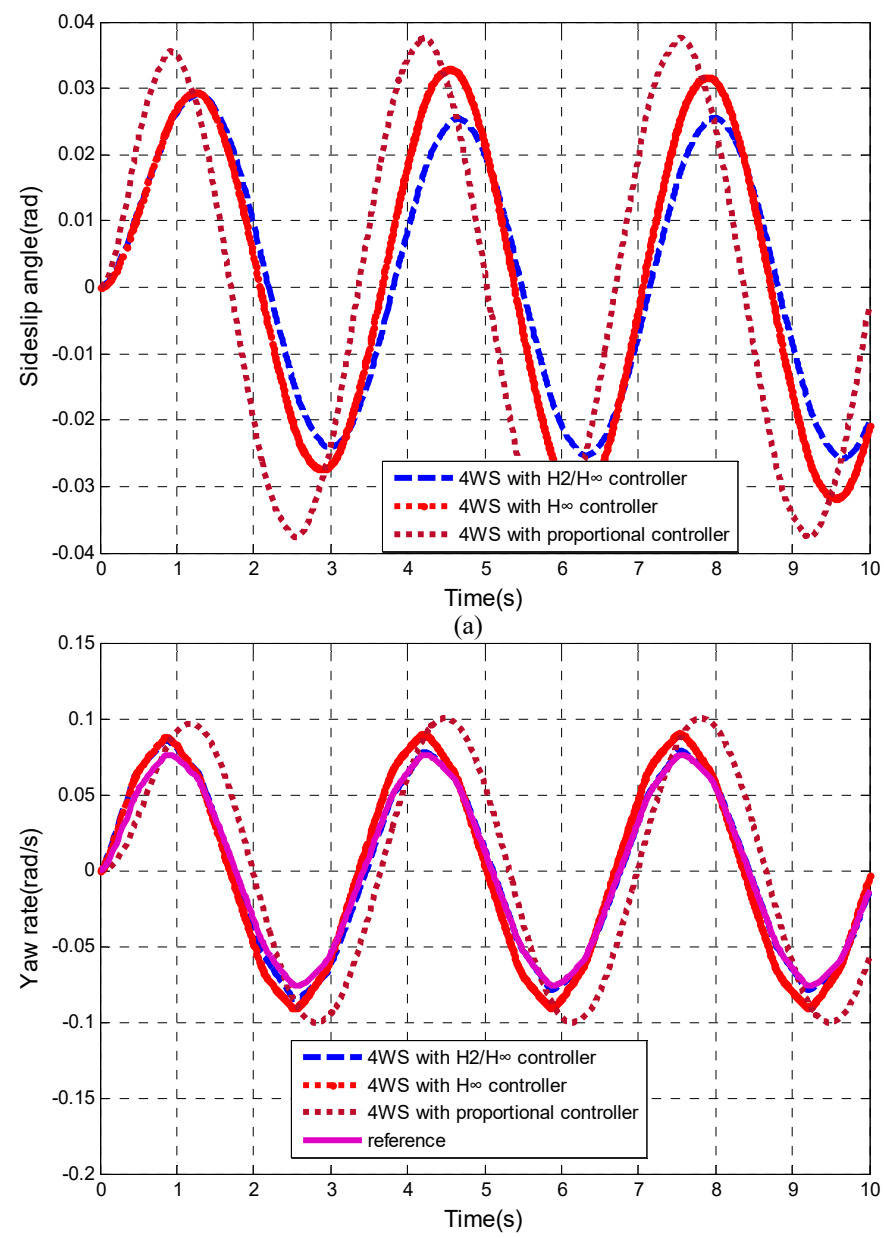

(b)

Figure 21. The sinusoidal responses of the front wheel angle: (a) sideslip angle response; (b) yaw rate response.

\subsection{Fishhook Maneuver}

The fishhook maneuver was performed to verify the system performance and robustness of the designed controller. The initial speed of the vehicle was taken as $108 \mathrm{~km} / \mathrm{h}$, and the road friction coefficient was set as 0.85 . Because the front wheel angle is commonly proportional to the steering 
wheel angle controlled by the driver, it was taken as the input signal, as shown in Figure 22. The simulation results for sideslip angle and yaw rate responses are displayed in Figure 23.

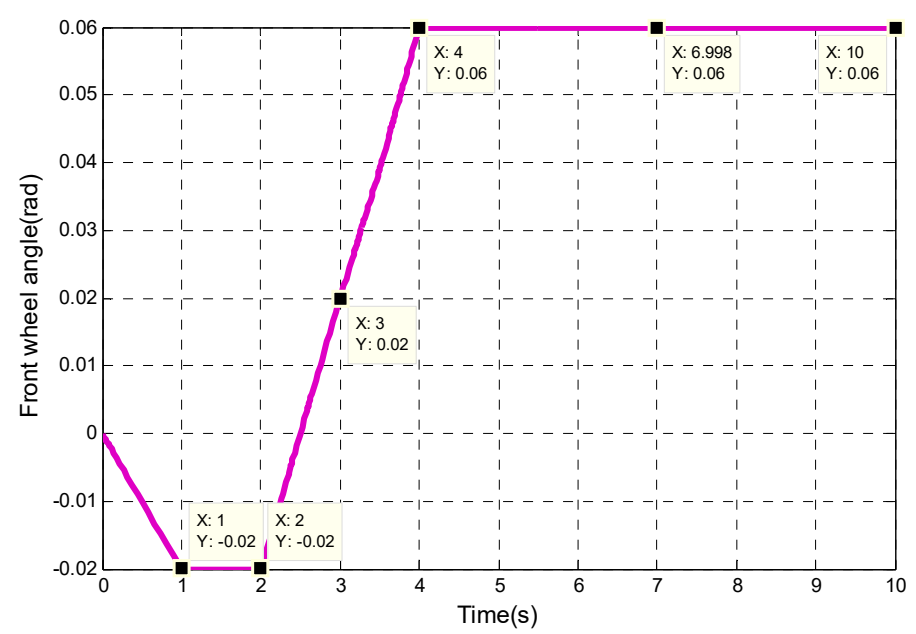

Figure 22. The front wheel angle under the fishhook maneuver.

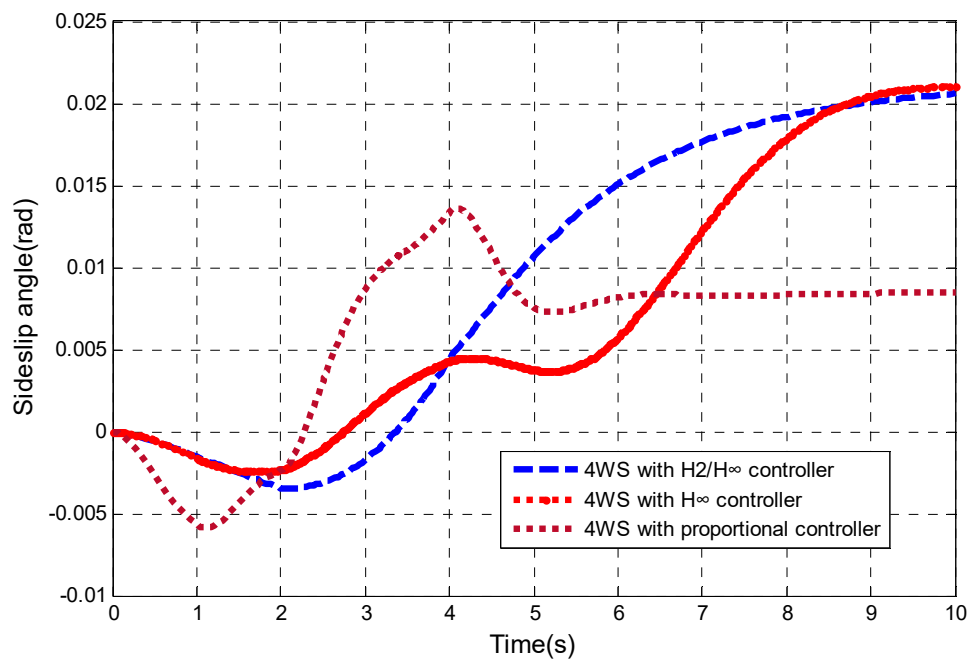

(a)

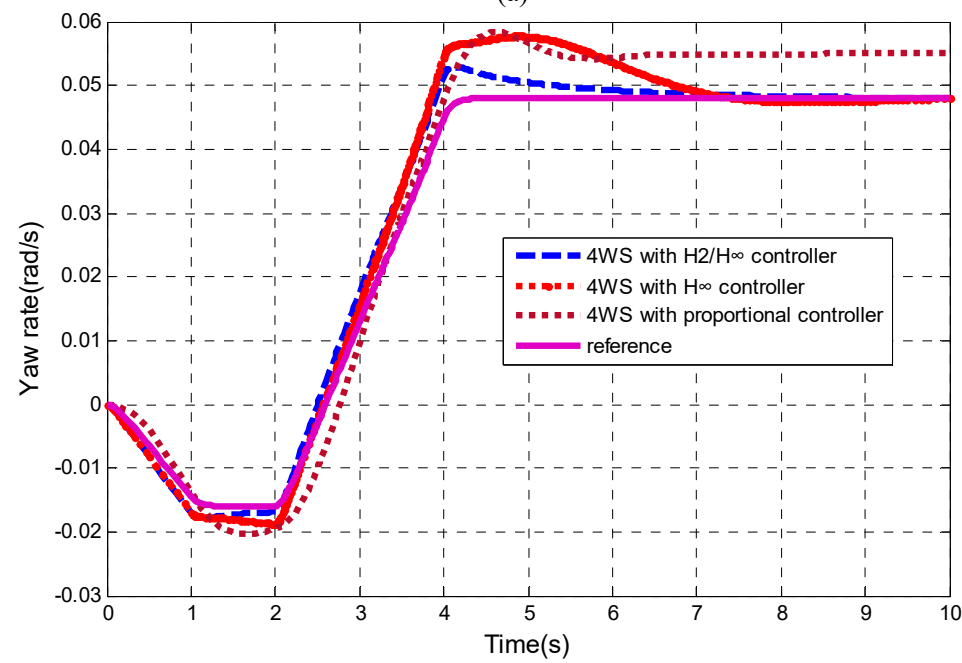

(b)

Figure 23. The fishhook maneuver simulation results: (a) sideslip angle response; (b) yaw rate response. 
In Figure 23a, we can see that the sideslip angle of the 4WS vehicle with the proportional controller had overshoot, and that of the $\mathrm{H} \infty$ controller showed fluctuations and responses that were slower than that of the $\mathrm{H} 2 / \mathrm{H} \infty$ controller. As can be seen in Figure 23b, the $4 \mathrm{WS}$ vehicle with the $\mathrm{H} 2 / \mathrm{H} \infty$ controller was able to track ideal yaw rate well, while those of the $\mathrm{H} \infty$ controller and the proportional controller had yaw rate tracking errors. In addition, the 4WS vehicle equipped with $\mathrm{H} 2 / \mathrm{H} \infty$ controller had faster response in terms of yaw rate. We can safely come to the conclusion that the 4WS system with the $\mathrm{H} 2 / \mathrm{H} \infty$ controller showed a better system performance than those of the $\mathrm{H} \infty$ controller and the proportional controller.

To compare the robustness performance of the proposed three controllers, the effects of side wind disturbance and yaw rate sensor noise were taken into account. The side wind, whose speed was set as $18 \mathrm{~m} / \mathrm{s}$ (Level $8: 17.2 \mathrm{~m} / \mathrm{s} \leq V_{\text {wind }} \leq 20.7 \mathrm{~m} / \mathrm{s}$ ), was used to simulate external interferences, as shown in Figure 24. The fishhook maneuver simulation under disturbances was conducted, and the simulation results are shown in Figure 25. As can be seen in Figure 25, under the disturbances in a 7-8 s period, the sideslip angle and the yaw rate of the $4 \mathrm{WS}$ vehicle equipped with the $\mathrm{H} 2 / \mathrm{H} \infty$ controller and the $\mathrm{H} \infty$ controller were slightly disturbed, while that of the proportional controller showed vibrations, and the sensitivities $\lambda_{\text {sen }}$ of the sideslip angle and the yaw rate to the disturbances were greater than 0.08 . It was concluded that the $\mathrm{H} 2 / \mathrm{H} \infty$ controller and the $\mathrm{H} \infty$ controller are more robust than the proportional controller.

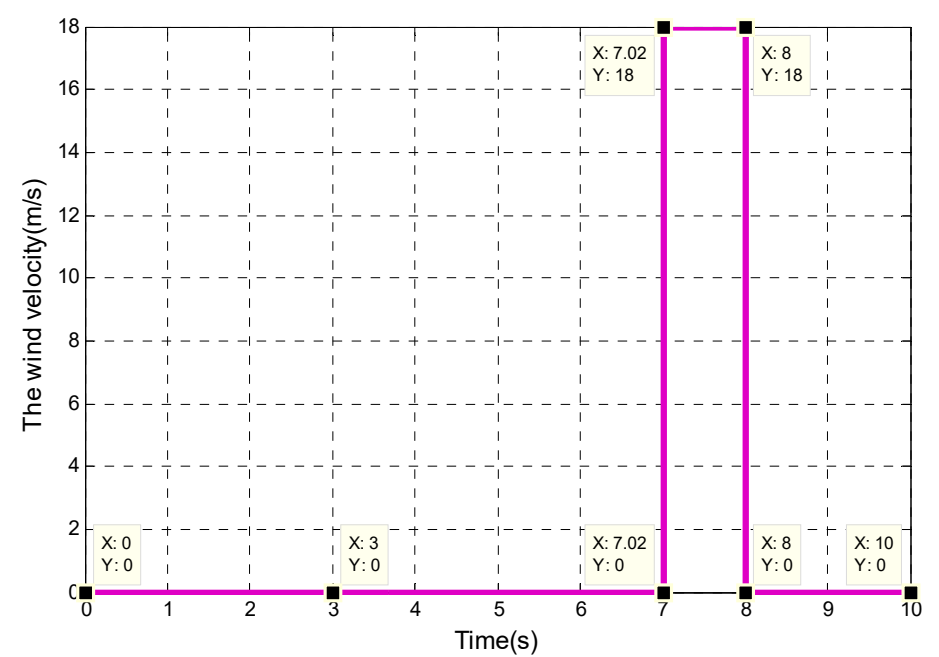

(a)

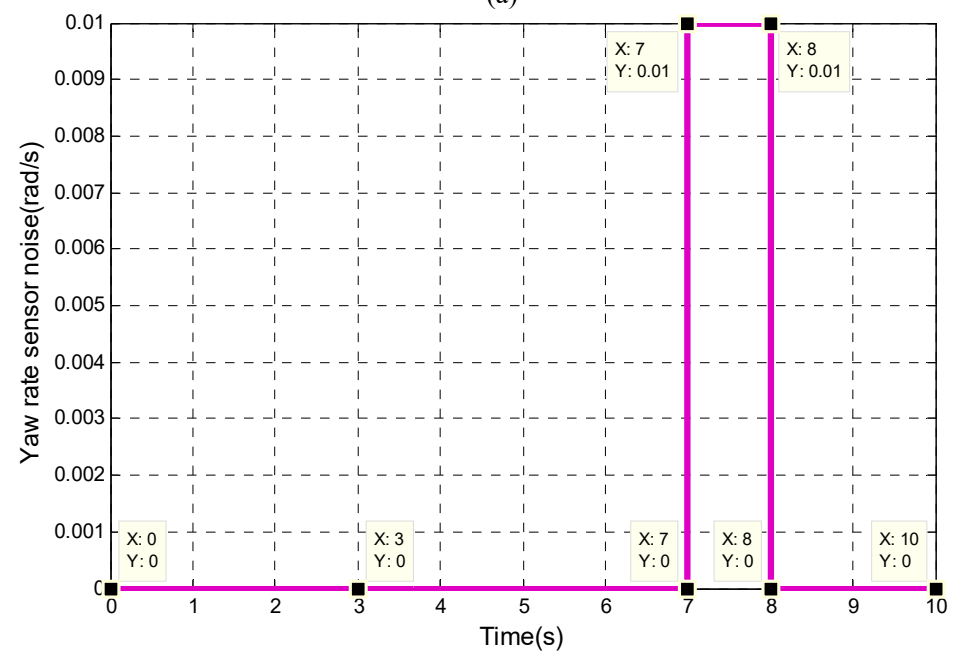

(b)

Figure 24. The disturbances inputs: (a) side wind; (b) yaw rate sensor noise. 


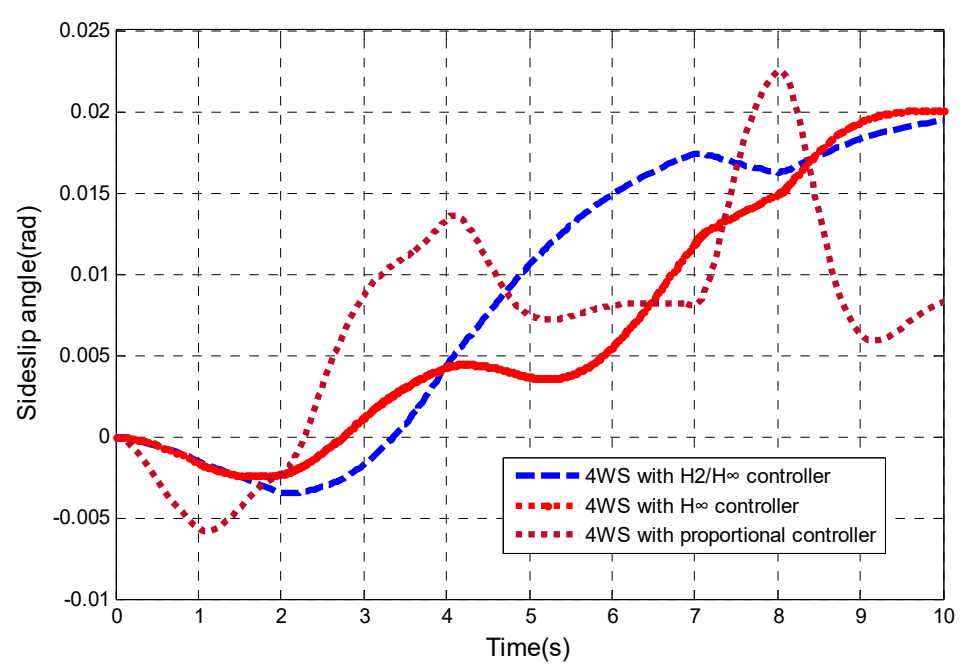

(a)

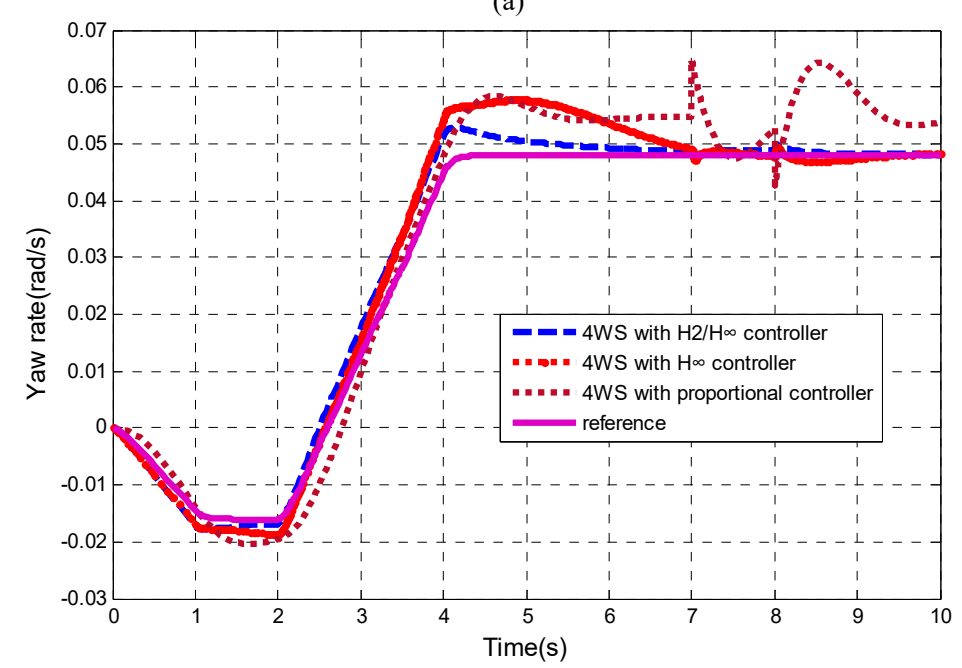

(b)

Figure 25. The fishhook maneuver simulation results under disturbances: (a) sideslip angle response; (b) yaw rate response.

\subsection{Double-Lane Change Maneuver}

The handing stability of the 4WS vehicle is closely related to the intention and operation of the driver, so the driver-vehicle closed-loop system is considered in this paper. The double-lane change maneuver is commonly applied to study the performance of the driver-vehicle closed-loop system, and here this maneuver was simulated in a Matlab/Simulink environment. The initial speed of the double-lane change maneuver was $72 \mathrm{~km} / \mathrm{h}$, and the road friction coefficient was set as 0.85 . The simulation results are shown in Figure 26.

In Figure 26a, we can see that the sideslip angle of the 4WS vehicle with the proportional controller was the highest. As can be seen in Figure 26b, the 4WS vehicle with the $\mathrm{H} 2 / \mathrm{H} \infty$ controller was able to track ideal yaw rate well, while those of the $\mathrm{H} \infty$ controller and the proportional controller had yaw rate tracking errors. In Figure 26c, although the 4WS vehicles with the proposed three kinds of controllers can track paths, the 4WS vehicles equipped with the $\mathrm{H} \infty$ controller and the proportional controller showed oscillations in the back straight path. Hence, considering the driver model, the 4WS vehicle with the $\mathrm{H} 2 / \mathrm{H} \infty$ controller had the best path tracking capability.

Based on the analysis of the simulation results of the four steering maneuvers, it was concluded that (1) the $\mathrm{H} 2 / \mathrm{H} \infty$ controller can improve the $4 \mathrm{WS}$ vehicle handing stability, which includes the yaw rate tracking ability and the path tracking performance, and that (2) the 4WS system with the $\mathrm{H} 2 / \mathrm{H} \infty$ 
controller outperformed those of the Ho controller and the proportional controller in terms of vehicle handing stability and robustness.

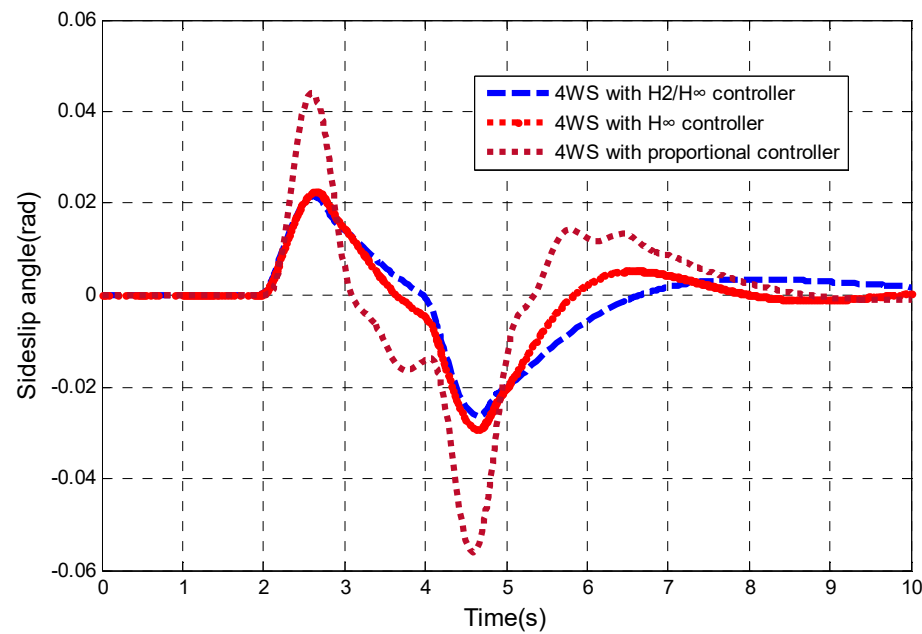

(a)

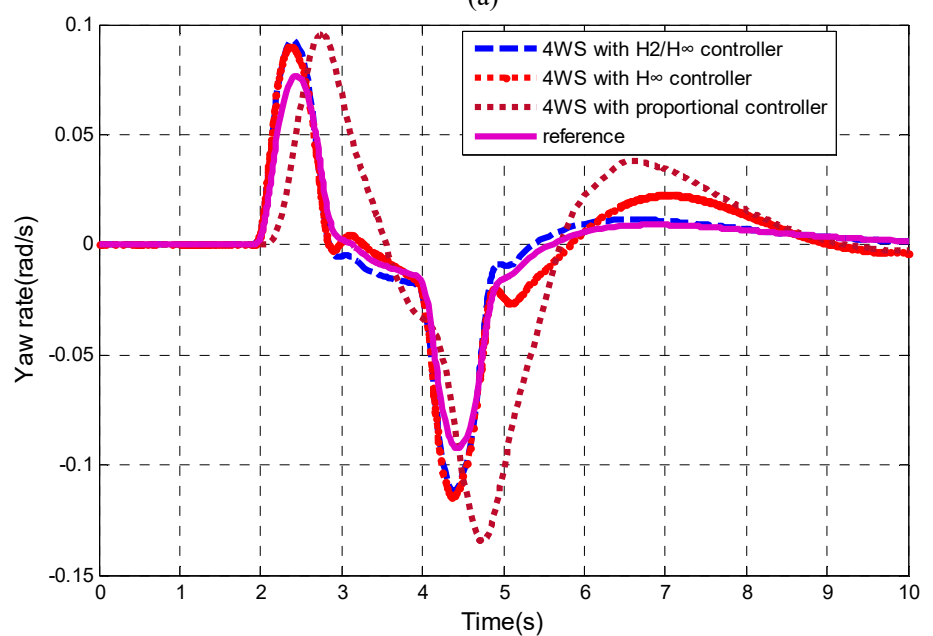

(b)

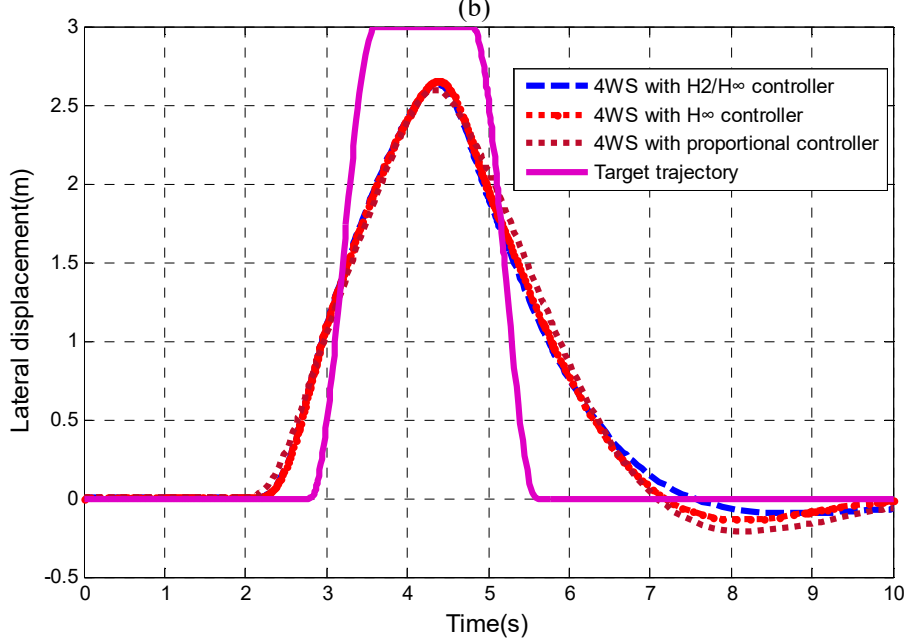

(c)

Figure 26. The double-lane change maneuver simulation results: (a) sideslip angle response; (b) yaw rate response; (c) lateral displacement response. 


\section{Hardware-in-the-Loop Experiments}

A rear wheel electrohydraulic system model was constructed to study the effect of the rear wheel electrohydraulic system on the handing stability of the $4 \mathrm{WS}$ vehicle. However, the mathematical model of the rear wheel electrohydraulic system is more ideal for practical steering mechanisms. An actual hydraulic steering system is highly non-linear and complex, and has a large number of interferences. That is to say, the modeling of the rear wheel electrohydraulic system involves uncertainties. The designed $\mathrm{H} 2 / \mathrm{H} \infty$ controller considers the modeling uncertainties to enhance the robustness of the 4WS control system. The step steering maneuver was used to verify the $\mathrm{H} 2 / \mathrm{H} \infty$ controller's robust stability against modeling uncertainties. In order to further demonstrate the $\mathrm{H} 2 / \mathrm{H} \infty$ controller's robustness against modeling uncertainties, a real rear wheel electrohydraulic system was established to conduct hardware-in-the-loop experiments. The experimental control block diagram is shown in Figure 27, and the experimental platform is displayed in Figure 28.

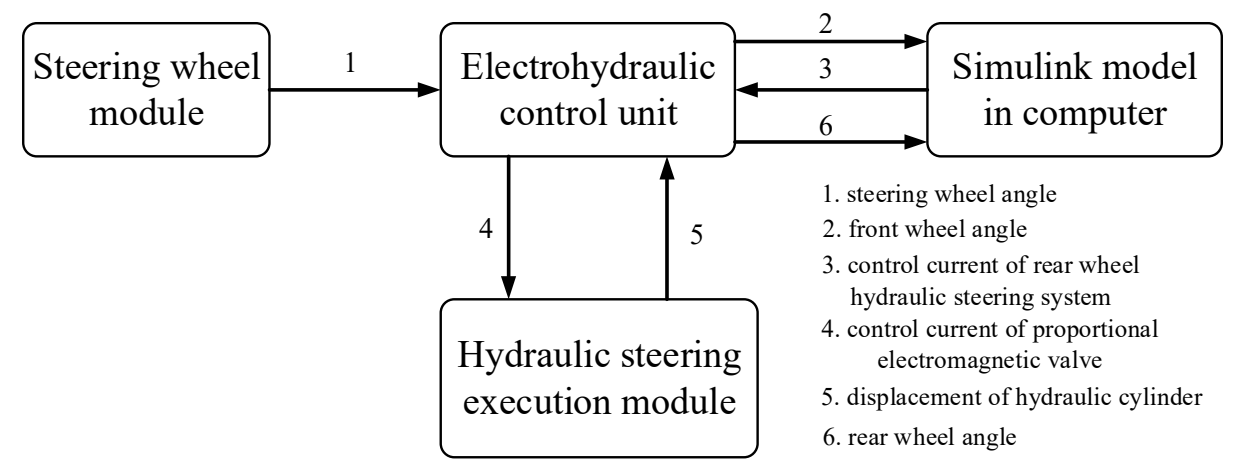

Figure 27. The experimental control block diagram.

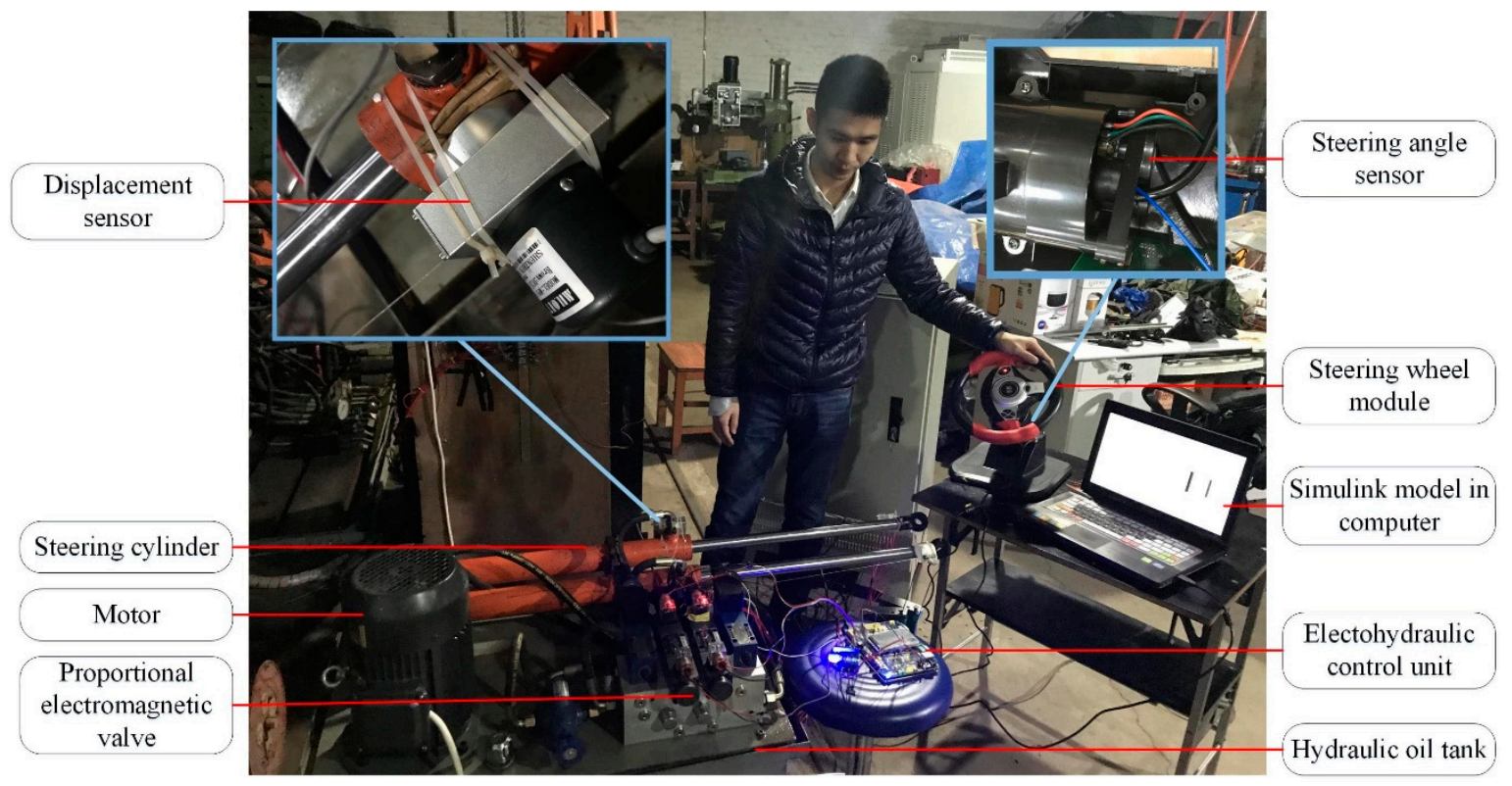

Figure 28. The experimental platform.

The experimental platform mainly consisted of four parts: the steering wheel module, the electrohydraulic control unit, the Simulink model in the computer, and the hydraulic steering execution module. The video game steering wheel, which is a Keteng brand device, was used as the steering wheel module, which was equipped with the steering angle sensor. The STM32f407 development board was used to design the electrohydraulic control unit. The Simulink model contained the nonlinear 8DOF vehicle model, the reference model, and the robust controller model. The rear 
wheel electrohydraulic system was composed of the hydraulic steering execution module and the electrohydraulic control unit. The hydraulic steering execution module was mainly made up of the proportional electromagnetic valve, the steering cylinder, the hydraulic pump, the hydraulic oil tank, the pressure compensated valve, and the relief valve. The schematic diagram of the hydraulic steering execution module is shown in Figure 29.

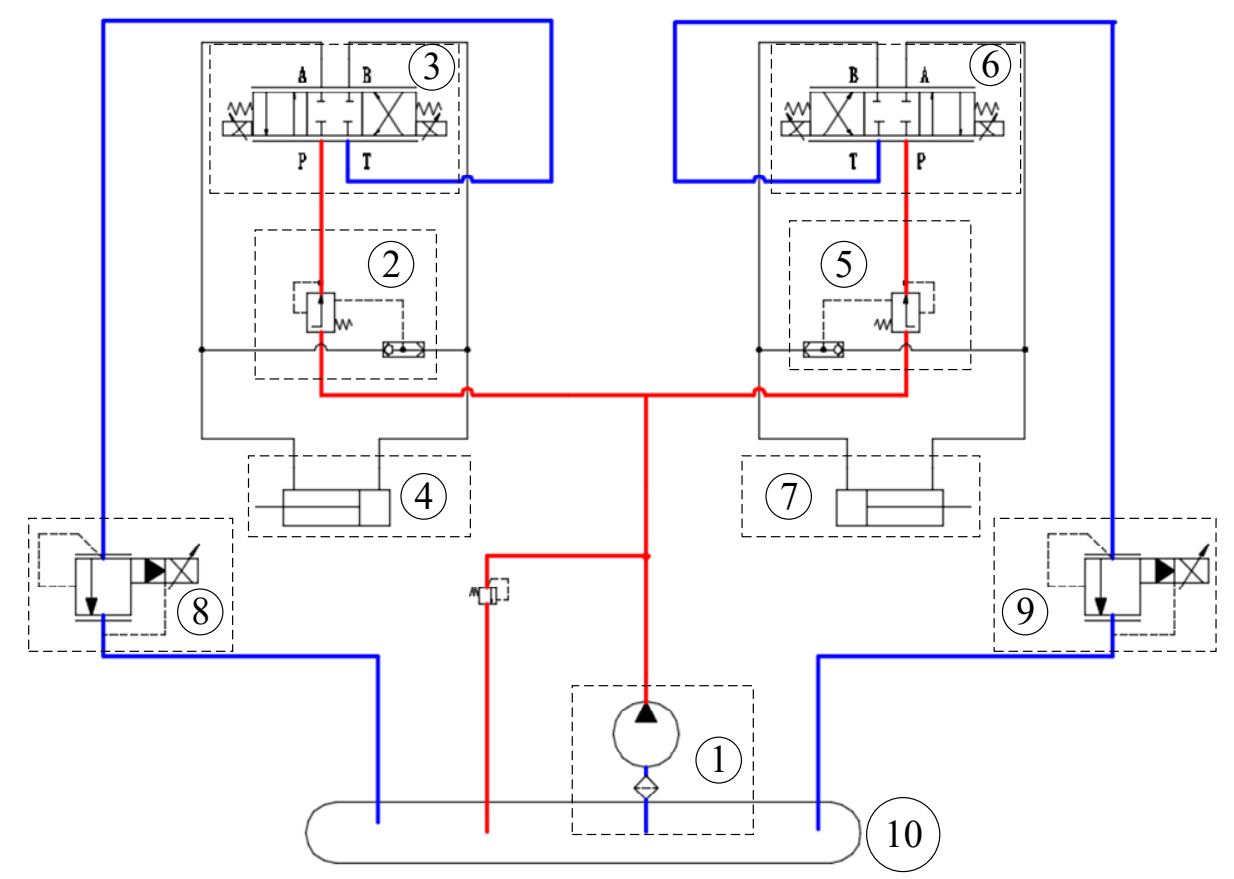

Figure 29. The schematic diagram of hydraulic steering execution module (1-hydraulic pump; 2,5-pressure compensated valve; 3,6-proportional electromagnetic valve; 4,7-steering cylinder; 8,9 -relief valve; 10 -hydraulic oil tank).

The steering wheel module was operated, and the steering wheel angle was then obtained, as shown in Figure 30. The front wheel angle was then calculated by the electrohydraulic control unit based on the transmission ratio of the steering system, which is shown in Figure 31.

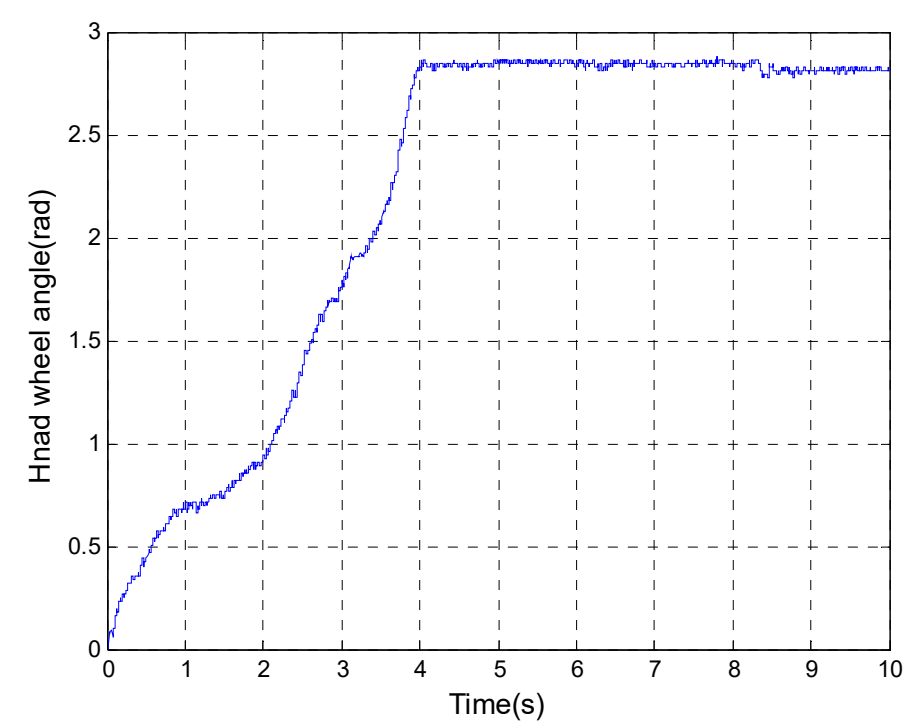

Figure 30. The steering wheel angle. 


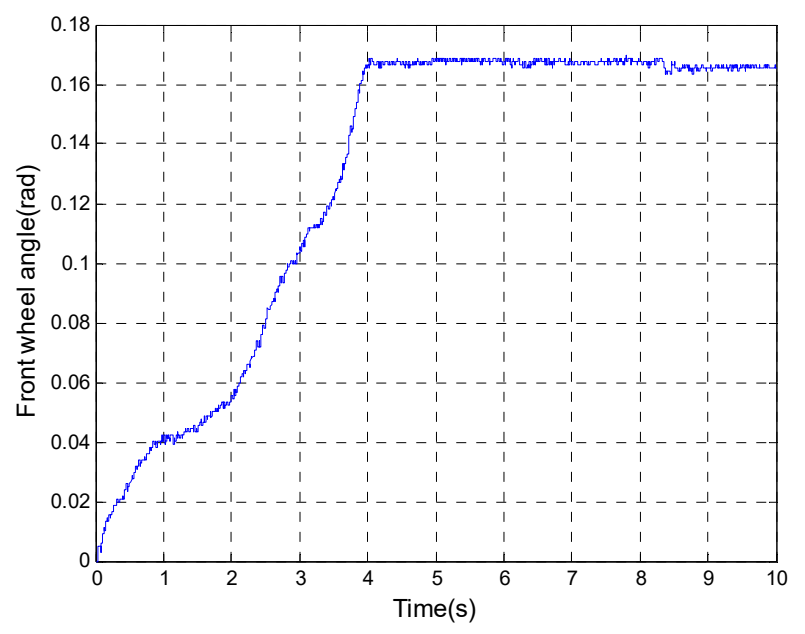

Figure 31. The front wheel angle.

Hardware-in-the-loop experiments under the $\mathrm{H} 2 / \mathrm{H} \infty, \mathrm{H} \infty$, and proportional control methods were conducted. The experimental results are shown in Figure 32.
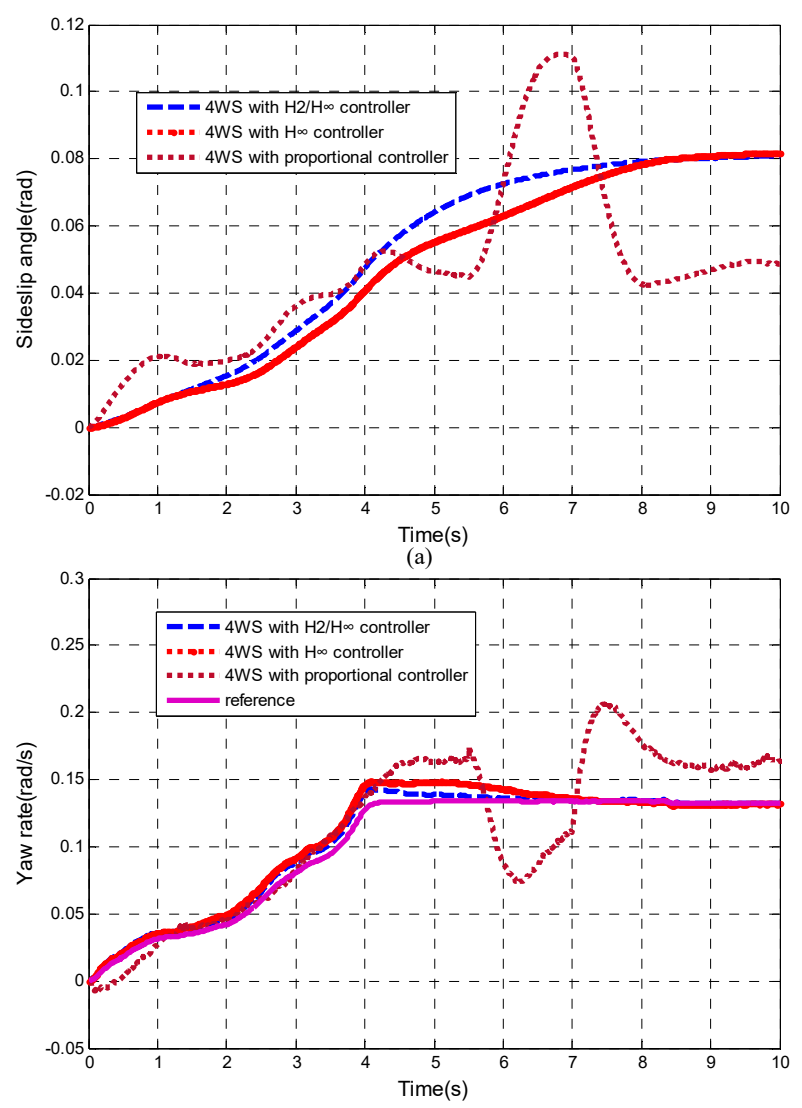

(b)

Figure 32. Experimental results: (a) sideslip angle; (b) yaw rate.

As can be seen in Figure 32, throughout the simulation time, the yaw rate and sideslip angle responses of the 4WS vehicle with the proportional controller showed a large number of slight oscillations, and large-amplitude vibrations occurred over a 5-8 s period. These two phenomena may be caused by errors (such as oil temperature change and internal leakage) in the hydraulic steering system and by the sudden pressure shock. However, we can see that the $\mathrm{H} 2 / \mathrm{H} \infty$ and $\mathrm{H} \infty$ controllers made the $4 \mathrm{WS}$ vehicle response stable in terms of yaw rate and sideslip angle, which illustrates that 
the $\mathrm{H} 2 / \mathrm{H} \infty$ and $\mathrm{H} \infty$ controllers, compared with the proportional controller, were more robust against the modeling uncertainties of the rear wheel electrohydraulic system.

The experimental results are consistent with the step steering maneuver simulation about the $\mathrm{H} 2 / \mathrm{H} \infty$ controller's robust stability against modeling uncertainties. We can conclude that the $\mathrm{H} 2 / \mathrm{H} \infty$ and $\mathrm{H} \infty$ controllers have great robustness against the modeling uncertainties and are superior to the proportional controller. Based on the simulation results, the $\mathrm{H} 2 / \mathrm{H} \infty$ controller, compared with the $\mathrm{H} \infty$ controller and the proportional controller, is more robust against the external disturbances and sensor noise of the vehicle model. Hence, the $\mathrm{H} 2 / \mathrm{H} \infty$ controller is more robust than the $\mathrm{H} \infty$ controller and the proportional controller. Moreover, the simulation results show that the 4WS system with the $\mathrm{H} 2 / \mathrm{H} \infty$ controller has better system performance than those of the $\mathrm{H} \infty$ control method and the proportional controller. In general, combining the simulation results with and the experimental results, the $4 \mathrm{WS}$ system with the $\mathrm{H} 2 / \mathrm{H} \infty$ controller outperformed those of the $\mathrm{H} \infty$ controller and the proportional controller in terms of vehicle handing stability and robustness.

\section{Conclusions}

In order to enhance the handling stability of the $4 \mathrm{WS}$ vehicle, a mixed $\mathrm{H} 2 / \mathrm{H} \infty$ robust controller was designed. The mathematical models including the linear $2 \mathrm{DOF}$ vehicle model, the nonlinear 8DOF vehicle model incorporating the Dugoff tire model, the driver model, and the rear wheel electrohydraulic system model were constructed to lay the model foundation for the controller design. The uncertainties including the 4WS vehicle modeling uncertainty, the rear wheel electrohydraulic system modeling uncertainty, the sensor noise, and the external disturbances were all taken into consideration in the controller design. Based on the yaw rate tracking strategy, the mixed $\mathrm{H} 2 / \mathrm{H} \infty$ controller was designed with three weighting functions to guarantee system performance, robustness performance, and the robust stability of the control system. Numerical simulations based on Matlab/Simulink and hardware-in-the-loop experiments were performed with the proposed control strategy to identify its performance. The simulation and experimental results show that the $\mathrm{H} 2 / \mathrm{H} \infty$ controller can improve the $4 \mathrm{WS}$ vehicle handling stability including the yaw rate tracking ability and the path tracking performance and that the $4 \mathrm{WS}$ system with the $\mathrm{H} 2 / \mathrm{H} \infty$ controller has better handling stability and robustness than those of the $\mathrm{H} \infty$ controller and the proportional controller.

Author Contributions: Conceptualization: F.-X.X. and X.-H.L.; methodology: F.-X.X. and C.Z. and W.C.; software: F.-X.X. and C.Z.; validation: F.-X.X., C.Z., and W.C.; writing-original draft preparation: F.-X.X., C.Z., and B.-W.C.; writing-review and editing: F.-X.X., C.Z., and B.-W.C.; project administration: F.-X.X. and X.-H.L.; funding acquisition: X.-H.L.

Funding: This research was funded by The National Key Research and Development Program of China under Grant No. 2016YFC0802904.

Acknowledgments: The authors would like to thank the institute of electrohydraulic control technology for engineering machinery at Jilin University and the Xuzhou Construction Machinery Group Co., Ltd. for supporting this research.

Conflicts of Interest: The authors declare no conflict of interest.

\section{References}

1. Yin, G.-D.; Chen, N.; Wang, J.-X.; Chen, J.-S. Robust control for 4WS vehicles considering a varying tire-road friction coefficient. Int. J. Autom. Technol. 2010, 11, 33-40. [CrossRef]

2. Higuchi, A.; Saitoh, Y. Optimal Control of Four Wheel Steering Vehicle. Veh. Syst. Dyn. 1993, 22, 397-410. [CrossRef]

3. Zhai, L.; Hou, R.; Sun, T.; Kavuma, S. Continuous Steering Stability Control Based on an Energy-Saving Torque Distribution Algorithm for a Four in-Wheel-Motor Independent-Drive Electric Vehicle. Energies 2018, 11, 350. [CrossRef]

4. Chen, Y.; Wang, J. Design and Evaluation on Electric Differentials for Overactuated Electric Ground Vehicles with Four Independent In-Wheel Motors. IEEE Trans. Veh. Technol. 2012, 61, 1534-1542. [CrossRef] 
5. Huang, F.; Fu, C.; Tang, X.; Hu, M. Study on stability and handling characteristics and control of four-wheel-drive electric vehicles. Adv. Mech. Eng. 2017, 9, 1687814017737725. [CrossRef]

6. Haytham, A.; Elhalwagy, Y.Z.; Wassal, A.; Darwish, N.M. Modeling and simulation of four-wheel steering unmanned ground vehicles using a PID controller. In Proceedings of the International Conference on Engineering and Technology, Cairo, Egypt, 19-20 April 2014.

7. Krishna, S.; Narayanan, S.; Ashok, S.D. Fuzzy logic based yaw stability control for active front steering of a vehicle. J. Mech. Sci. Technol. 2014, 28, 5169-5174. [CrossRef]

8. Gao, L.; Jin, L.; Zheng, Y.; Li, K.Y. Design of radial basis function neural network compound controller for four wheel steering vehicle. J. Jilin Univ. 2016, 46, 366-372.

9. Lin, C.; Peng, C.L. Mixed H $\infty / \mathrm{H} 2$ Output Feedback Stability Control for Dual-Motor Independent Drive Electric Vehicle. Adv. Mater. Res. 2013, 658, 602-608. [CrossRef]

10. Hang, P.; Chen, X.; Fang, S.; Luo, F. Robust control for four-wheel-independent-steering electric vehicle with steer-by-wire system. Int. J. Autom. Technol. 2017, 18, 785-797. [CrossRef]

11. Yin, G.; Chen, N.; Li, P. Improving Handling Stability Performance of Four-Wheel Steering Vehicle via $\mu$-Synthesis Robust Control. IEEE Trans. Veh. Technol. 2007, 56, 2432-2439. [CrossRef]

12. Sun, Y.; Li, N.; Shen, M.; Wei, Z.; Sun, G. Robust H-infinity control of uncertain linear system with interval time-varying delays by using Wirtinger inequality. Appl. Math. Comput. 2018, 335, 1-11.

13. Chayaopas, N.; Assawinchaichote, W. A novel approach to robust H-infinity integral control for TS fuzzy systems. Comput. Appl. Math. 2018, 37, 954-977. [CrossRef]

14. Chang, X.-H.; Yang, G.-H. New results on output feedback $\mathrm{H} \infty$ control for linear discrete-time systems. IEEE Trans. Autom. Control 2014, 59, 1355-1359. [CrossRef]

15. Cao, J.; Sivasamy, R.; Rakkiyappan, R. Sampled-data Ho synchronization of chaotic Lur'e systems with time delay. Circuits Syst. Signal Process. 2016, 35, 811-835. [CrossRef]

16. Dharani, S.; Rakkiyappan, R.; Cao, J. Robust stochastic sampled-data $\mathrm{H} \infty$ control for a class of mechanical systems with uncertainties. J. Dyn. Syst. Meas. Control-Trans. ASME. 2016, 137, 1-14. [CrossRef]

17. Zhao, W.-Z.; Li, Y.-J.; Wang, C.-Y.; Zhao, T.; Gu, X.-Y. Ho control of novel active steering integrated with electric power steering function. J. Cent. South Univ. 2013, 20, 2151-2157. [CrossRef]

18. Li, M.; Jia, Y. Decoupling control in velocity-varying four-wheel steering vehicles with H $\infty$ performance by longitudinal velocity and yaw rate feedback. Veh. Syst. Dyn. 2014, 52, 1563-1583. [CrossRef]

19. Zhang, J.; Sun, W.; Feng, Z. Vehicle yaw stability control via H-infinity gain scheduling. Mech. Syst. Signal Process. 2018, 106, 62-75. [CrossRef]

20. Qin, G.; Zou, J. H-infinity Control of Four-Wheel-Independent-Drive Electric Vehicles with Random Time-Varying Delays. Math. Probl. Eng. 2015, 2015, 245493. [CrossRef]

21. Kurishige, M.; Nishihara, Q.; Kumamoto, H. A new control strategy to reduce steering torque without perceptible vibration for vehicles equipped with electric power steering. J. Vib. Acoust. 2010, 132, 054504. [CrossRef]

22. Moriwaki, K. Autonomous steering control for electric vehicles using nonlinear state feedback $\mathrm{H} \infty$ control. Nonlinear Anal. Theory Methods Appl. 2005, 63, 2257-2268. [CrossRef]

23. Siqueira, A.A.; Terra, M.H.; Ishihara, J.Y.; Barbeiro, T.L. Underactuated Manipulator Robot Control via H-2, $\mathrm{H}$-infinity, H-2/H-infinity, and mu-Synthesis Approaches: A Comparative Study. J. Braz. Soc. Mech. Sci. Eng. 2009, 31, 279-288.

24. Ye, M.; Wang, Q.; Jiao, S. Robust $\mathrm{H} 2 / \mathrm{H} \infty$ Control for the Electrohydraulic Steering System of a Four-Wheel Vehicle. Math. Probl. Eng. 2014, 2014, 208019. [CrossRef] [PubMed]

25. Stefanovski, J. On general H2 control: From frequency to time domain. Int. J. Control 2010, 83, $2519-2535$. [CrossRef]

26. Wu, K.N.; Wang, J. Mixed H2/Ho control of synchronization for coupled partial differential systems. Int. J. Robust Nonlinear Control 2017, 27, 1397-1418.

27. Prime, Z.; Cazzolato, B.; Doolan, C. Mixed H2/Hinf Scheduling Control Scheme for a Two Degree-of-Freedom Aeroelastic System Under Varying Airspeed and Gust Conditions. In Proceedings of the AIAA Guidance, Navigation and Control Conference and Exhibit, Honolulu, HI, USA, 18-21 August 2008.

28. Zhao, W.; Wang, C. Mixed H2/H $\infty$ road feel control of EPS based on genetic algorithm. Sci. China Technol. Sci. 2012, 55, 72-80. [CrossRef] 


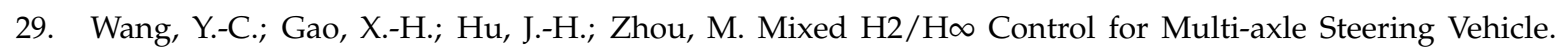
J. Chongqing Inst. Technol. (Nat. Sci.) 2008, 22, 6-10.

30. Yue, S.; Fan, Y. Hierarchical Direct Yaw-Moment Control System Design for In-Wheel Motor Driven Electric Vehicle. Int. J. Autom. Technol. 2018, 19, 695-703. [CrossRef]

31. Mousavinejad, I.; Kazemi, R. Variable structure controller design for steer-by-wire system of a passenger car. J. Mech. Sci. Technol. 2014, 28, 3285-3299. [CrossRef]

32. Smith, D.E.; Starkey, J.M. Effects of Model Complexity on the Performance of Automated Vehicle Steering Controllers: Model Development, Validation and Comparison. Veh. Syst. Dyn. 1995, 24, 163-181. [CrossRef]

33. Dugoff, H.; Fancher, P.S.; Segel, L. An Analysis of Tire Traction Properties and Their Influence on Vehicle Dynamic Performance. SAE Trans. 1970, 79, 1219-1243.

34. Guo, K.H. Vehicle Handling Dynamics; Jilin Science\& Technology Press: Changchun, China, 1991.

35. Ji, X.; Wu, J.; Zhao, Y.; Liu, Y.; Zhao, X. A new robust control method for active front steering considering the intention of the driver. Proc. Inst. Mech. Eng. Part D-J. Autom. Eng. 2015, 229, 518-531. [CrossRef]

36. Ono, E.; Takanami, K.; Iwama, N.; Hayashi, Y.; Hirano, Y.; Satoh, Y. Vehicle integrated control for steering and traction system by $\mu$-synthesis. Automatica 1994, 30, 1639-1647. [CrossRef]

37. Gu, D.-W.; Petkov, P.H.; Konstantinov, M.M. Robust Control Design with MATLAB, Serial of Advanced Textbooks in Control and Signal Processing; Springer: Berlin, Germany, 2013.

38. Zhengren, A. Vehicle Movement and Manipulation; Mechanical Industry Press: Beijing, China, 1998.

(C) 2019 by the authors. Licensee MDPI, Basel, Switzerland. This article is an open access article distributed under the terms and conditions of the Creative Commons Attribution (CC BY) license (http://creativecommons.org/licenses/by/4.0/). 